\title{
Optical Investigation of a Partial Fuel Stratification Strategy to Stabilize Overall Lean Operation of a DISI Engine Fueled with Gasoline and E30
}

\author{
Cinzia Tornatore ${ }^{1, *}$ and Magnus Sjöberg ${ }^{2}$ (D) \\ 1 Istituto di Scienze e Tecnologie per 1'Energia e la Mobilità Sostenibili (STEMS), Italian National Research \\ Council, Via Marconi 4, 80125 Napoli, Italy \\ 2 Sandia National Laboratories, MS 9053, P.O. Box 969, Livermore, CA 94551-0969, USA \\ * Correspondence: cinzia.tornatore@stems.cnr.it
}

Citation: Tornatore, C.; Sjöberg, M. Optical Investigation of a Partial Fuel Stratification Strategy to Stabilize Overall Lean Operation of a DISI Engine Fueled with Gasoline and E30. Energies 2021, 14, 396. https:// doi.org/10.3390/en14020396

Academic Editors: Michele Battistoni and Chaouki Habchi

Received: 6 December 2020

Accepted: 5 January 2021

Published: 12 January 2021

Publisher's Note: MDPI stays neutral with regard to jurisdictional claims in published maps and institutional affiliations.

Copyright: (c) 2021 by the authors. Licensee MDPI, Basel, Switzerland. This article is an open access article distributed under the terms and conditions of the Creative Commons Attribution (CC BY) license (https:// creativecommons.org/licenses/by/ $4.0 /)$.

\begin{abstract}
This paper offers new insights into a partial fuel stratification (PFS) combustion strategy that has proven to be effective at stabilizing overall lean combustion in direct injection spark ignition engines. To this aim, high spatial and temporal resolution optical diagnostics were applied in an optically accessible engine working in PFS mode for two fuels and two different durations of pilot injection at the time of spark: $210 \mu$ s and $330 \mu$ s for E30 (gasoline blended with ethanol by 30\% volume fraction) and gasoline, respectively. In both conditions, early injections during the intake stroke were used to generate a well-mixed lean background. The results were compared to rich, stoichiometric and lean well-mixed combustion with different spark timings. In the PFS combustion process, it was possible to detect a non-spherical and highly wrinkled blue flame, coupled with yellow diffusive flames due to the combustion of rich zones near the spark plug. The initial flame spread for both PFS cases was faster compared to any of the well-mixed cases (lean, stoichiometric and rich), suggesting that the flame propagation for PFS is enhanced by both enrichment and enhanced local turbulence caused by the pilot injection. Different spray evolutions for the two pilot injection durations were found to strongly influence the flame kernel inception and propagation. PFS with pilot durations of $210 \mu$ s and $330 \mu$ s showed some differences in terms of shapes of the flame front and in terms of extension of diffusive flames. Yet, both cases were highly repeatable.
\end{abstract}

Keywords: spark ignition engine; GDI engine; partial fuel stratification; lean operation; E30; ethanol

\section{Introduction}

The need for a reduction in $\mathrm{CO}_{2}$ and pollutant emissions from mobile sources, has in the last few decades led to the development of high efficiency engines for the automotive sector through the use of several different technologies [1]. With respect to spark ignition (SI) engines, gasoline direct injection (GDI) has been extensively adopted since it allows considerable gains in fuel economy, which together with exhaust emissions represent the most crucial points in terms of spark ignition engine regulations.

The direct injection engine shows four main benefits compared to the port-fuel injection counterpart: first of all, the fuel directly injected into the combustion chamber evaporates and cools the charge, which in turn suppresses knock and increases the volumetric efficiency. Secondly, it is easier to achieve an exact control of the amount of fuel to control the air-fuel ratio, especially for transient operation. Third, with this configuration, less fuel is wasted through the air exchange processes [2]. Lastly, GDI engines can potentially use fuel injection during the compression stroke to create a fully or partially stratified charge.

Usually, GDI engines operate under nominally homogeneous and stoichiometric conditions. Such operation shows some limits in terms of thermal efficiency, mainly: pumping losses caused by intake throttling, high heat-transfer losses and unfavorable thermodynamic properties of the combustion products due to high combustion temperatures [3]. 
Fuel-lean operation can mitigate these limitations of stoichiometric operation to obtain better specific fuel consumption and emissions. On the other hand, low values of global fuel-air equivalence ratio $(\varphi)$ with homogeneous charge chamber make flame speeds too low, inhibiting a stable creation and development of the flame kernel. Thus, a stable and fast combustion is very difficult to obtain under highly lean conditions and this corresponds to unacceptable vehicle drivability [4].

In a study by Sjöberg and Zeng [5], lean well-mixed operation with gasoline and E30 (i.e., gasoline with $30 \%$ ethanol by volume) was studied in combination with several aiding techniques. A multi-pulse transient plasma ignition system allowed some extension of the lean-stability limit compared to a conventional spark-ignition system. Intake-gas preheating also promoted inflammation and shifted the onset of combustion instability to lower fuel-air equivalence ratios. The combination of enhanced ignition and intake-air heating enabled reasonably stable mixed-mode combustion, which is a combination of deflagration and end-gas autoignition. Hence, the referred paper indicated several viable paths for stable and more efficient lean SI operation.

As mentioned above, direct injection engines enable operation with a fully stratified charge, which provides strong potential for increased fuel economy [6], but such an operation can also pose challenges with partial burns and misfires [7]. Direct injection engines also enable operation with a fuel-injection strategy referred to as partial fuel stratification (PFS), which has been successfully applied to provide benefits for low-temperature combustion (LTC) engines $[8,9]$ that operate with autoignition-based combustion without a spark plug. PFS couples mixture stratification and homogeneous lean charge throughout the combustion chamber: it is characterized by a first injection early in the intake stroke that forms a well-mixed background charge. Then a small injection (pilot) takes place in the compression stroke to create fuel stratification that affects the sequential autoignition process.

PFS can also be used in SI engines. With a pilot injection just before the spark discharge, a fast kernel growth can be ensured even for fuel-lean condition while a globally lean mixture offers the potential for high thermodynamic efficiency. In recent works, PFS has been applied at different operating conditions and for different fuels. In particular, in [10], PFS was tested in the same test facility as the present work for a wide range of loads and intake temperatures. The direct-injection spark-ignition (DISI) engine was fueled with gasoline and E85. The experiments demonstrated that, once ignited by a normal spark, the pilot-injected fuel operated as a super igniter of the well-mixed ultra-lean charge allowing repeatable deflagration without misfires. The occurrence and intensity of end-gas autoignition were found to be critical for achieving high combustion and thermal efficiencies, as well as for stable indicated mean effective pressure (IMEP) for lean operation.

To put the current study of lean PFS operation in context with conventional lean well-mixed SI combustion, Figure 1 plots selected well-mixed results from Reference [5] together with the new PFS conditions investigated in the present paper. In Figure 1a, the coefficient of variation (COV) of net IMEP $\left(\mathrm{IMEP}_{\mathrm{n}}\right)$ is shown for well-mixed conditions versus $\varphi$ ranging from rich (1.3) to lean conditions (around 0.55). It is clear that when the fuel-air mixture is leaned out, the IMEP stability decreases until it becomes unacceptable for $\varphi$ below 0.55 for both fuels.

Figure $1 \mathrm{~b}$ compares the Apparent Heat Release Rate (AHRR) for gasoline at wellmixed conditions for 4 selected equivalence ratio values. These curves, averaged over 500 consecutive engine cycles, provide an insight regarding the effect of $\varphi$ on heat release rate: Rich $(\varphi=1.29)$ and stoichiometric $(\varphi=1.00)$ combustion are characterized by a short dwell between the spark timing and the main combustion thanks to a high flame speed. For lean mixtures, the low flame speed induces a slower overall heat release rate that, in the case of $\varphi=0.54$, shows a broad profile and the need to apply a very early spark. The IMEP instability is, thus, associated with a slow flame propagation that shows up with a slow and low AHRR. For operation with a well-mixed charge, this drop in flame speed becomes a significant challenge from the perspective of achieving reliable ignition and fast deflagration throughout the reactants. 


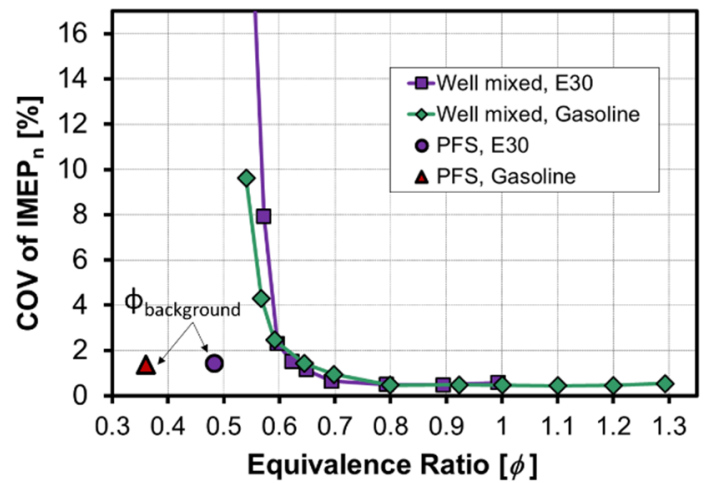

(a)

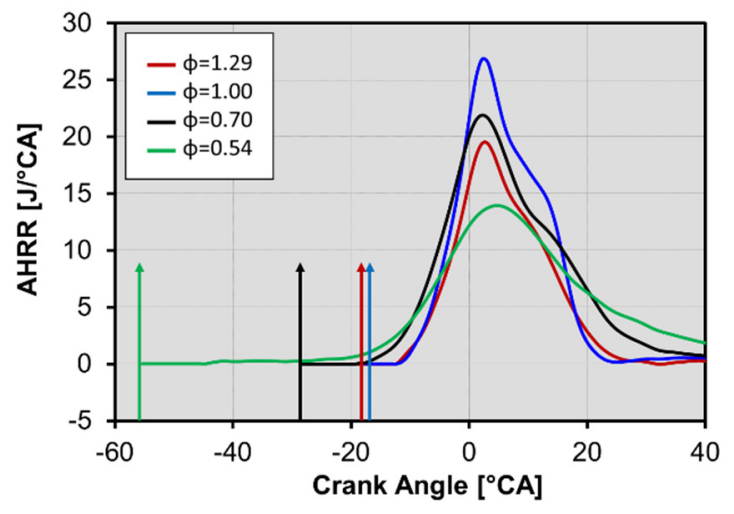

(b)

Figure 1. (a) COV of IMEP for well mixed E30 and gasoline at different $\varphi$ 's (with $T_{\text {in }}=30{ }^{\circ} \mathrm{C}$ ) and for PFS at the conditions investigated in the present paper; (b) AHRR for gasoline in well-mixed conditions. The spark timing for each condition is indicated as a vertical arrow. The gasoline fueling rate of $15.6 \mathrm{mg} /$ cycle was kept constant while the intake pressure varied between 37 and $77 \mathrm{kPa}$ to change the $\varphi$.

Figure 1a also plots COV of IMEP versus $\varphi$ for the PFS strategies that will be investigated in the present paper with gasoline and E30. In this case, the $\varphi$ value reported in the graph corresponds to $\varphi$ of the well-mixed background charge. The very low levels of COV of IMEP associated with PFS demonstrate that this strategy can be used to stabilize the combustion, even for conditions with very lean reactants in areas away from the spark-plug. The PFS combustion cases of the current study have similarities with Mazda's Spark Controlled Compression Ignition (SPCCI) implementation, which was studied by Nakai et al. [11].

Starting with these considerations, the present paper aims at offering new insights into the PFS combustion strategy by applying high spatial and temporal resolution optical diagnostics from the fuel injection until the end of the combustion process. A detailed quantitative analysis of the phenomena will also be reported through the comparison of PFS process with well-mixed combustion for different values of $\varphi$ and spark timing.

\section{Experimental Setup}

\subsection{GDI Research Engine}

The experimental activity was carried out in a single-cylinder four-valve research engine whose main specifications are reported in Table 1 . It can be used in two nearly identical configurations: an all-metal one for continuously fired performance testing and an optical one for application of optical diagnostics. Figure 2 shows a cross section of the combustion chamber (left) and a picture of the piston top (right).

Table 1. Engine Specifications.

\begin{tabular}{cc}
\hline Specification & Value \\
\hline Displacement (l) & 0.552 \\
Bore (mm) & 86.0 \\
Stroke (mm) & 95.1 \\
Connecting Rod Length (mm) & 166.7 \\
Geometric Compression Ratio & $12: 1$ \\
Intake Valve Diameter (mm) & 35.1 \\
Exhaust Valve Diameter (mm) & 18 \\
Intake Valve Angle Relative Cylinder Axis $\left(^{\circ}\right)$ & 30.1 \\
Exhaust Valve Angle Relative Cylinder Axis & 16 \\
Swirl/Tumble index (one intake valve deactivated) & $27 / 0.62$ \\
\hline
\end{tabular}



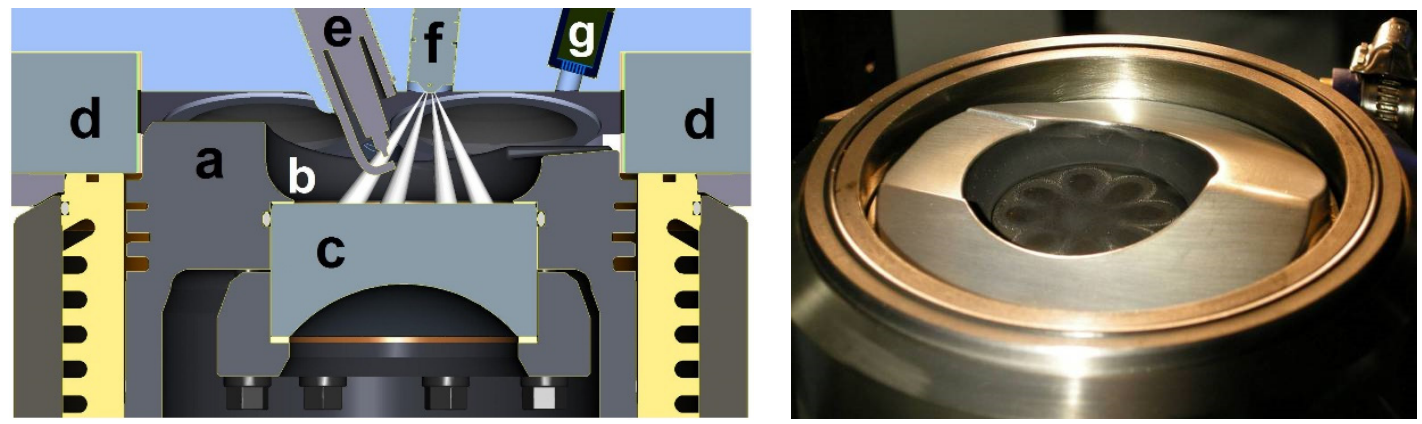

Figure 2. Left: scheme of the cross-section of combustion chamber at TDC with (a)—piston, (b)—piston bowl, (c) — pistonbowl quartz window or metal blank, (d) — pent-roof quartz window or metal blank, (e)—spark plug, (f) —fuel injector, and (g)-pressure transducer; right: Picture of all-metal piston and cylinder.

The engine features an extended Bowditch type piston and a pent-roof geometry combustion chamber with two intake and two exhaust valves. The in-cylinder pressure was acquired through an uncooled Kistler 6125C piezoelectric sensor (Figure 2g) coupled with a Kistler 5010B charge amplifier.

In the optical configuration, the engine is equipped with two quartz windows: one in the end of the pent-roof section closest to the injector, and one in the piston bowl. Both windows are flat on the combustion chamber side, just as the metal window blanks used for the all-metal performance testing. The piston window is concave on the crank-case side, creating a negative lens for a larger field of view. The piston bowl is shaped to aid the fuel stratification, and its rim has a slight cut-out on one side to facilitate a better view into the bowl via the optical pent roof side windows (Figure 2d). The cut-out also improves the use of the side window for illumination or detection of the liquid fuel sprays.

Fuel is supplied to the combustion chamber by a Bosch 8-hole solenoid injector with stepped hole (min.dia $=0.125 \mathrm{~mm})$ and symmetric hole orientation $\left(60^{\circ}\right.$ included angle). The injector is oriented in such a way that two of the fuel sprays straddle the spark-plug electrode. This avoids direct impact of the liquid fuel onto the spark electrodes. The fuel was pressurized using a hydraulic piston accumulator by applying nitrogen at 170 bar on the top of the piston. Due to friction in the seals of the piston in the accumulator, the fuel pressure at the fuel injector was typically around 166-167 bar.

Based on results obtained in previous investigations, one of the intake valves is deactivated to increase in-cylinder swirl and tumble levels and thus to achieve repeatable combustion for fully stratified operation [12].

In this study, the crank angle degrees $\left({ }^{\circ} \mathrm{CA}\right.$ or $\mathrm{CAD}$ ) are referenced to TDC of the combustion stroke (ATDC): negative numbers correspond to intake and compression strokes.

\subsection{Optical Experimental Setup}

High spatial and temporal resolution imaging was applied during injection and combustion processes. Figure 3 shows the optical experimental system.

Two different CMOS cameras were used in order to allow the visualization of the processes that take place in the engine from two different fields of view. A color CMOS camera Phantom v611 camera provided flame imaging through the piston-bowl window via a $45^{\circ}$ Bowditch mirror and a camera lens with a focal length of $180 \mathrm{~mm}$, fully open with f/2.8. A monochrome Phantom v710 camera was placed to acquire images from a lateral point of view. Phantom v611 and v710 CMOS sensors are sensitive in the 350-900 nm range, and no filters were used. Therefore, broadband luminosity was collected both from flame chemiluminescence and from thermal emission of hot combustion products. 

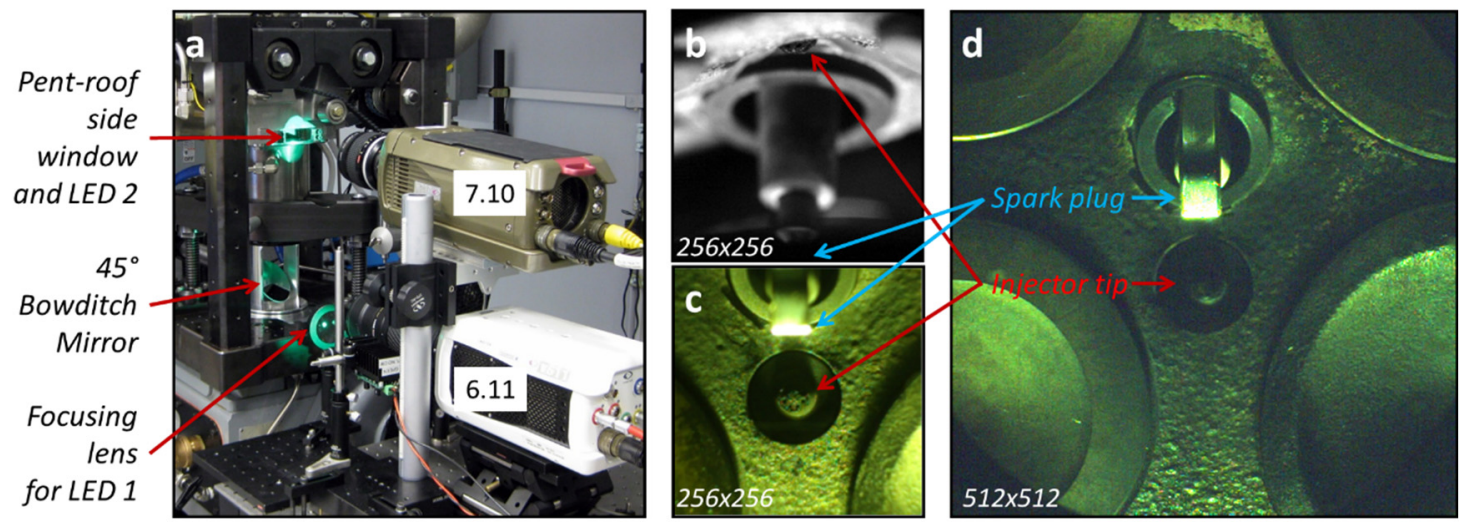

Figure 3. (a) Optical experimental setup and $(\mathbf{b}, \mathbf{c})$ reference images that correspond to the dual-camera spray imaging and (d) to the combustion process imaging.

The optimal setup was chosen according to the process that was investigated. In Table 2, a resume of the experimental setup and settings is reported. The focus of the camera lens was set on the tip of the spark-plug electrode for a crank angle of -30 CAD. The cameras were synchronized to the crank-shaft encoder of the engine.

Table 2. Experimental Setup and Settings for the optical measurements.

\begin{tabular}{|c|c|c|c|}
\hline Process & External Light & Visualization from Lateral & Visualization from Bottom \\
\hline $\begin{array}{l}\text { Well-mixed } \\
\text { combustion }\end{array}$ & No led used & No & $\begin{array}{c}\text { Phantom v611 } \\
\text { Exposure time: } 45 \mu \mathrm{s} \\
(0.27 \text { CAD at } 1000 \mathrm{rpm}) \\
\text { Frame rate: } 20,000 \mathrm{fps}(0.3 \mathrm{CAD} \text { between } \\
\text { start of exposure of two consecutive } \\
\text { images at } 1000 \mathrm{rpm}) .\end{array}$ \\
\hline $\begin{array}{c}\text { Spray } \\
\text { Visualization }\end{array}$ & $\begin{array}{l}\text { Two LED were used to } \\
\text { illuminate the spray via the } \\
\text { pent roof and the } \\
\text { bottom windows. } \\
\text { Light-pulse duration: } 3 \mu \mathrm{s}\end{array}$ & $\begin{array}{c}\text { Phantom v710 } \\
\text { Exposure time: } 7.8 \mu \mathrm{s} \\
(0.05 \text { CAD at } 1000 \mathrm{rpm}) \\
\text { Frame rate: } 60,000 \mathrm{fps} \\
\text { (0.1 CAD between start of } \\
\text { exposure of two consecutive } \\
\text { images at } 1000 \mathrm{rpm}) .\end{array}$ & $\begin{array}{c}\text { Phantom v611 } \\
\text { Exposure time: } 4.1 \mu \mathrm{s} \\
(0.025 \mathrm{CAD} \text { at } 1000 \mathrm{rpm}) \\
\text { Frame rate: } 60,000 \mathrm{fps}(0.1 \mathrm{CAD} \text { between } \\
\text { start of exposure of two consecutive } \\
\text { images at } 1000 \mathrm{rpm}) .\end{array}$ \\
\hline PFS combustion & $\begin{array}{l}\text { LED was used to } \\
\text { illuminate the spray } \\
\text { before the start of } \\
\text { the combustion via the pent } \\
\text { roof window. } \\
\text { Light-pulse duration: } 3 \mu \mathrm{s}\end{array}$ & No & $\begin{array}{c}\text { Phantom v611 } \\
\text { Exposure time: } 45 \mu \mathrm{s} \\
(0.27 \text { CAD at } 1000 \mathrm{rpm}) \\
\text { Frame rate: } 20,000 \mathrm{fps} \\
\text { (0.3 CAD between start of exposure of } \\
\text { two consecutive images at } 1000 \mathrm{rpm}) \text {. }\end{array}$ \\
\hline
\end{tabular}

\subsection{Engine Operating Conditions and Fuels}

Haltermann certification gasoline and E30 fuel were used for this work. The E30 fuel was obtained through in-house blending of $70 \%$ by volume of certification gasoline and $30 \%$ by volume of anhydrous high-purity ethanol. Selected properties of the gasoline and E30 fuel are listed in Table 3. The Research Octane Number (RON) of E30 blend is high, this tends to make it challenging to achieve end-gas auto ignition in comparison with the use of lower-RON fuels.

Two different combustion modes were selected for this work: Well-mixed and Partial Fuel Stratification. The average engine speed was maintained constant at $1000 \mathrm{rpm}$ and the coolant temperature was set to $90^{\circ} \mathrm{C}$. 
Table 3. Fuel properties for gasoline and E30 used in this work.

\begin{tabular}{ccc}
\hline Fuel Property & Haltermann EPA Tier II Certification Gasoline & E30 \\
\hline Research Octane Number (RON) & 96.9 & 104.9 \\
Motor Octane Number (MON) & 88.5 & 90.7 \\
A/F stoichiometric & 14.54 & 12.81 \\
Lower Heating Value, gas phase fuel $(\mathrm{MJ} / \mathrm{kg})$ & 42.8 & 37.8 \\
LHV for stoichiometric charge $(\mathrm{MJ} / \mathrm{kg})$ & 2.75 & 2.74 \\
\hline
\end{tabular}

A detailed representation of injections and spark timing is reported in Figure 4 for the selected engine operating conditions. In the well-mixed mode, three different air to fuel ratios were investigated: Lean, Stoichiometric, and Rich. To obtain these well-mixed conditions, 3 early direct injections were carried out during the intake stroke. The interval between the starts of early injections was kept at 15 CAD and the same injection duration was used for each fuel injection. The injection duration was determined by the targeted air to fuel ratio level and by the fuel being used.

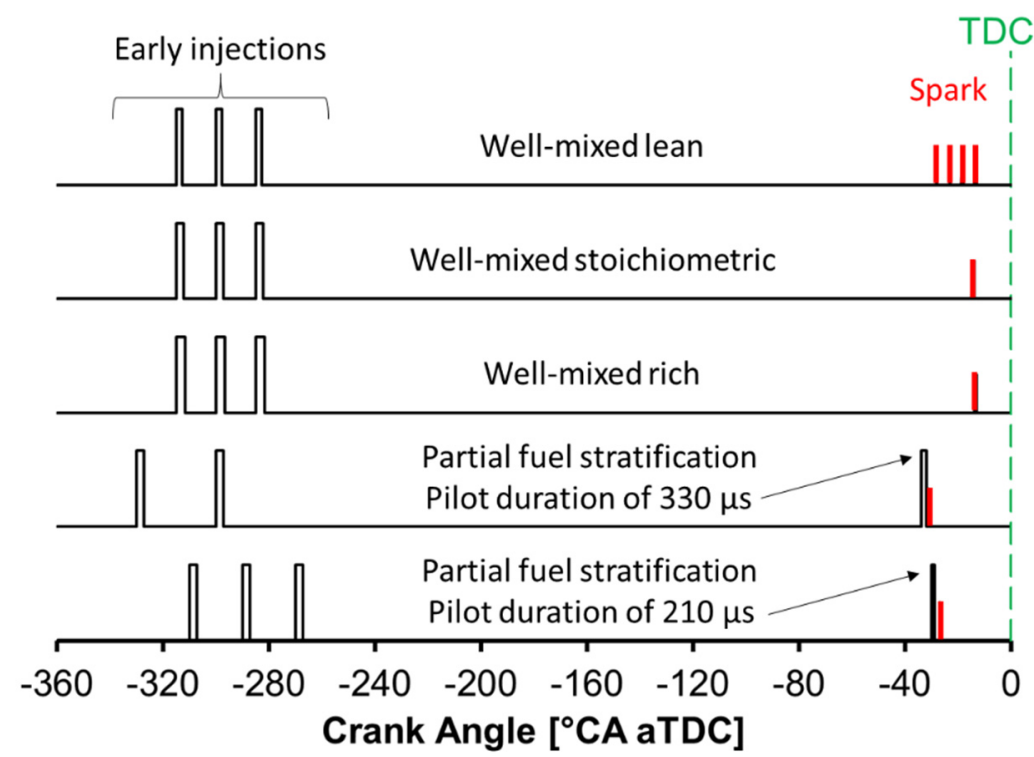

Figure 4. Timing of events in the selected engine operating conditions.

In Partial Fuel Stratification (PFS) mode, a small amount of fuel was added to the well-mixed background charge through a late injection called the "Pilot". The spark timing (ST) for the PFS modes was set at 3 CAD after the electrical signal for the start of the pilot-injection. Two different durations of Pilot injection were investigated; a shorter $210 \mu \mathrm{s}$ pilot for operation with E30 fuel, and a longer $330 \mu$ s pilot for operation with gasoline. The amount of fuel injected during the pilot is $0.84 \mathrm{mg}$ E30 for $210 \mu \mathrm{s}$ and $3.4 \mathrm{mg}$ gasoline for $330 \mu \mathrm{s}$. The corresponding chemical energy is $31.8 \mathrm{~J}$ for the E30 case and $145 \mathrm{~J}$ for the gasoline case (based on the pilot mass multiplied with the lower heating value). To aid the analysis presented in Appendix B, data were collected also for fired engine operation with only pilot injection corresponding to each of the PFS combustion cases. For the two PFS cases, the timing and number of early injections varied, partly because the gasoline fuel allowed an earlier SOI without generating smoke due to wall wetting. (Generally, the earliest possible injection is preferred since it provides more time for fuel-air mixing, but smoke generation due to piston-top impingement must be avoided).

For all engine operation, the primary ignition coil was energized for $30 \mathrm{CAD}$, rendering a nominal spark energy of $106 \mathrm{~mJ}$.

\section{Experimental Procedure and Data Analysis}

In the all-metal engine configuration, the data were acquired when all measured parameters were stable after several minutes of steady-state operation. The fuel pressure, 
in-cylinder pressure, intake and exhaust pressure were acquired for 500 successive cycles using a resolution of $0.1 \mathrm{CAD}$. For this paper, such steady-state operation was only used for the well-mixed $\varphi$-sweeps shown in Figure 1. In order to limit the thermal stress on the quartz windows, a Fire3-Skip9 sequence was used for fired operation with the optical engine configuration and the total run time was typically limited to around $5 \mathrm{~min}$. The IMEP $_{n}$ instability was quantified through the COV of IMEP ${ }_{n}$ for both all-metal and optical operation. To compute the 10,50,90\% burn points, the AHRR is integrated over the crankangle range for which AHRR is positive. This computation of burn points is executed in a traditional manner whereby the integral of AHRR is allowed to rise from 0 to $100 \%$ for every cycle, irrespective of the actual combustion efficiency.

For CADs before ST, the plotted reactant temperature corresponds to the massaveraged charge temperature, which is computed based on the ideal gas law. To estimate the end-gas reactant temperature ( $\mathrm{T}_{\text {end-gas }}$ ) after spark timing, Equation (1) is used assuming that the compression caused by the combustion-induced pressure rise after the spark timing is isentropic and adiabatic.

$$
\mathrm{T}_{\text {end-gas }}=\mathrm{T}_{\text {avg@ST }} \cdot\left(\frac{\mathrm{P}_{\text {actual }}}{\mathrm{P}_{\mathrm{ST}}}\right)^{\frac{\gamma-0.07-1}{\gamma-0.07}},
$$

In this equation $\mathrm{T}_{\mathrm{avg} @ \mathrm{ST}}$ and $\mathrm{P}_{\mathrm{ST}}$ represent the mass-averaged gas temperature and the in-cylinder pressure at $\mathrm{ST}$, respectively. $\mathrm{T}_{\text {avg@ST }}$ is computed based on the ideal-gas law. For the operating points selected in this work, ST falls in the range of -31 to -13 CAD, so heat transfer is expected to have a moderate influence [13], causing some bias of $\mathrm{T}_{\text {avg@ST }}$. This translates to some uncertainty in $\mathrm{T}_{\text {end-gas }}$, so these values should be interpreted with care. $\mathrm{P}_{\text {actual }}$ corresponds to the pressure at any crank angle after ST. For each operating condition, the value of $\gamma$, i.e., the ratio of specific heats, is obtained from the measured pressure rise and computed rise of mass-averaged gas temperature that occur between Intake Valve Closing and ST. In Equation (1), the value 0.07 is subtracted from $\gamma$ as a first-order compensation for the reduction of $\gamma$ that takes place when the gas temperature keeps rising after ST, as demonstrated in the Appendix of Reference [5].

The optical data were acquired on the third fired cycle of each sequence: in this way it was assured that residuals were representative of the operating condition in terms of temperature and composition. In each PFS combustion cycle, spray and flame images were acquired. To be able to distinguish liquid fuel from early flame luminosity, the LED light pulse was only applied on every other image acquired after ST. Effectively, this makes the liquid fuel "blink" when studying a movie sequence, revealing its existence (See Supplementary Materials for an example video). Determined by the memory size of the camera, for PFS combustion, 70 cycles were imaged with 300 images per cycle. For well-mixed combustion imaging, 30 (gasoline) or 45 (E30) cycles were acquired for each operating condition. For spray imaging, 30 injections were recorded for each injection duration.

\subsection{Postprocessing of the Optical Data}

Custom procedures were developed for the post processing of optical data relative to different phenomena. For the evaluation of fuel-spray penetration, a program was developed in a Labview-Vision (National Instruments) environment, with the main steps summarized in Figure 5. From the original image (a) color plane or intensity plane (depending on the kind of image, color or grayscale) is extracted to obtain a grayscale image (b). Then a threshold is applied. After the image is binarized, binary morphological functions are applied to improve the resulting binary image. In particular, the operation "remove small objects", among the advanced morphological operations is used. Then the lines corresponding to the spray paths are traced (c) and edge detector finds and labels all edges along the line selected (d). 

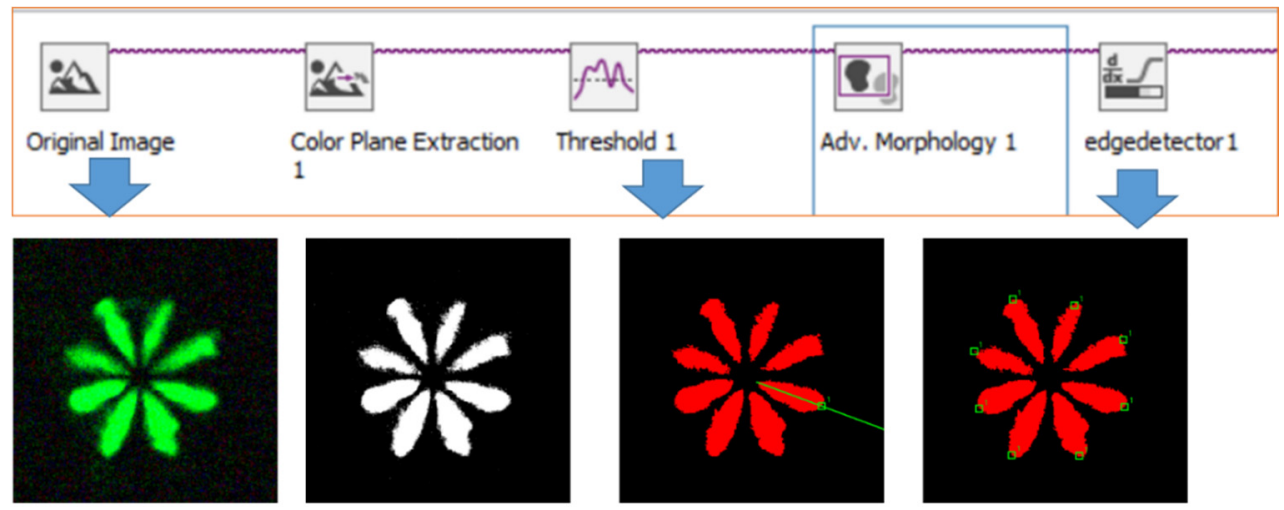

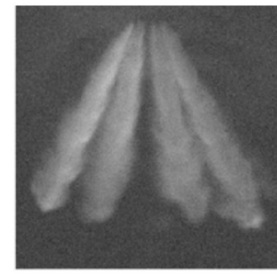

a

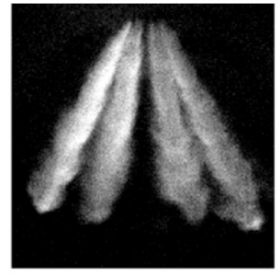

b

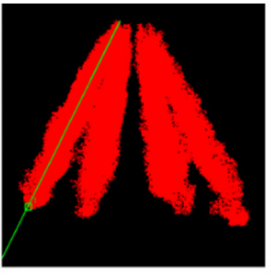

c

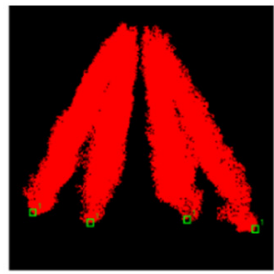

d

Figure 5. Steps of Vision program for evaluation of fuel spray penetration: (a) original image, (b) grayscale image, (c) binary image (d) edges along the selected spray path lines.

The penetrations are estimated for all the visible jets and for each image sequence. An average value is then calculated.

Image J (TM) software was used to calculate the mean value of luminosity in selected regions of interest. The following procedure was developed and used:

1. The mean gray value in the selected regions is calculated for each frame. A mean value over all the sequences is calculated.

2. The background value is subtracted.

3. Plots are all normalized by their peak individual value.

Another image processing procedure was developed in a Labview-Vision (National Instruments) environment to evaluate the characteristics of the combustion process. Starting from the images acquired by the CMOS camera, the script allows modifying brightness, contrast, and gamma values, then color plane or intensity plane is extracted to obtain a grayscale image and a threshold is applied to convert the image into a binary image. Small objects are removed, and as a final step, morphological flame parameters are evaluated. In detail, the enflamed area and coordinates of the luminous center of mass are calculated for each binarized image. The program evaluates the CAD at which $50 \%$ of the processed cycles shows a flame touching the limits of the field of view. In this paper, all optical data points corresponding to the CADs where the flame front has approached the boundary of the field of view, are represented with crosses and should be interpreted with caution.

\section{Results-Well-Mixed Combustion}

Well-mixed combustion for different $\varphi$ 's was analyzed in detail through application of flame chemiluminescence during the whole combustion process. The results obtained for well-mixed conditions provide a fundamental knowledge basis that aids the development of understanding of the PFS combustion process. It can be noted that under PFS conditions, the flame propagates through regions of varying fuel concentrations since the $\varphi$ distribution is not uniform in the combustion chamber. For lean well-mixed operation, different spark timings were investigated: in this way the limits of a well-mixed lean combustion were examined together with the effect of spark timing on the combustion process.

Combustion characteristics for well-mixed operation were analyzed for gasoline and E30 at three different $\varphi$ 's: 1.0 for stoichiometric condition (by definition); 0.7 for the lean cases; and 1.3 for the rich cases. Table 4 resumes the operating conditions for well-mixed 
combustion and the global engine parameters such as the $\mathrm{IMEP}_{n}$, its variability (Standard Deviation-SD and COV), and the CADs for 10, 50, and 90\% of Mass Fuel Burned (MFB).

Table 4. Operating conditions of the engine in its optical configuration for well-mixed mode combustion analysis. Engine speed is $1000 \mathrm{rpm}$.

\begin{tabular}{|c|c|c|c|c|c|c|c|c|c|c|}
\hline \multirow{2}{*}{$\begin{array}{c}\text { Fuel } \\
\text { label }\end{array}$} & \multicolumn{6}{|c|}{ Gasoline } & \multicolumn{4}{|c|}{ E30 } \\
\hline & Lean 1 & Lean 2 & Lean 3 & Lean 4 & Stoichiometric & Rich & Lean 2 & Lean 3 & Stoichiometric & Rich \\
\hline$\varphi(-)$ & 0.7 & 0.7 & 0.7 & 0.7 & 1 & 1.3 & 0.7 & 0.7 & 1 & 1.3 \\
\hline $\begin{array}{l}\text { Spark Timing } \\
\text { (CAD ATDC) }\end{array}$ & -28 & -23 & -18 & -13 & -14 & -13 & -23 & -18 & -14 & -13 \\
\hline Inj. Duration $\left(\mu s^{*} 3\right)$ & 377 & 377 & 377 & 377 & 450 & 535 & 390 & 390 & 450 & 565 \\
\hline Intake Press. (kPa) & 52.2 & 52.2 & 52.2 & 52.2 & 52.2 & 52.2 & 53.0 & 53.0 & 53.0 & 53.0 \\
\hline Intake Temp. $\left({ }^{\circ} \mathrm{C}\right)$ & 54.2 & 54.2 & 54.2 & 54.2 & 54.2 & 54.2 & 55.2 & 55.2 & 55.2 & 55.2 \\
\hline $\operatorname{IMEP}_{\mathrm{n}}(\mathrm{kPa})$ & 279.7 & 270.3 & 253.8 & 220.8 & 419.1 & 435.6 & 281.7 & 267.9 & 423.0 & 438.3 \\
\hline $\mathrm{IMEP}_{\mathrm{n} \_\mathrm{SD}}(\mathrm{kPa})$ & 8.2 & 8.2 & 25.1 & 28.7 & 1.6 & 2.6 & 11.25 & 14.89 & 2.16 & 1.96 \\
\hline COV of IMEP $(\%)$ & 2.93 & 3.03 & 9.89 & 12.99 & 0.38 & 0.60 & 3.99 & 5.52 & 0.51 & 0.48 \\
\hline CAD $10 \%$ MFB & -1.07 & 2.31 & 7.06 & 13.12 & 1.15 & 1.57 & 2.83 & 7.63 & 1.31 & 1.55 \\
\hline CAD $50 \%$ MFB & 10.69 & 14.90 & 21.27 & 30.69 & 9.35 & 9.42 & 15.65 & 21.93 & 9.61 & 9.44 \\
\hline CAD $90 \%$ MFB & 30.18 & 35.33 & 44.25 & 56.86 & 19.81 & 18.28 & 34.29 & 42.82 & 19.4 & 18.4 \\
\hline
\end{tabular}

For stoichiometric and rich conditions, the selected STs correspond to the spark timings

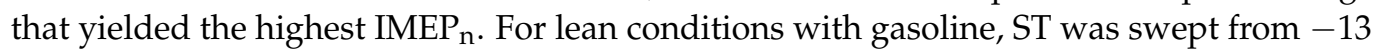
(similar to stoichiometric and rich condition) to -28 with a step of 5 CADs for gasoline. For the subsequent data acquisition of lean E30 combustion, only the intermediate values of ST were examined ( -18 and -23$)$ because those were deemed to be most relevant for a concurrent spectroscopic study, which is briefly summarized in Appendix A.

Figure 6 reports the pressure traces and the rates of heat release for gasoline and E30 for all the selected well-mixed conditions. It should be highlighted that AHRR traces are affected by interference from the spark coil when the spark discharge begins. This "error" helps identify the ST, but it does not bias the data analysis, so for this reason it has not been corrected. However, the pressure traces have been cleaned up to not bias the pressure-based computation of the in-cylinder charge temperature. As expected, for lean conditions, advancing the spark ignition induces an increase in maximum peak pressure and an advance in the heat release rate. This results in an increase in IMEP $_{n}$ together with a reduction in its standard deviation (SD) (cf. Table 4).

For each condition, in order to identify one representative engine cycle, the mean in-cylinder pressure, mass fraction burnt and AHRR were calculated as mean values over 30-45 cycles, corresponding to the cycles for which flame imaging was performed. With respect to the cycle-resolved flame visualization, the mean intensity of each frame was obtained as the average of the pixel luminosity and "mean luminosity vs CAD" was obtained for each condition. A comparison was carried out between these mean values and the ones for the individual cycles. The cycles corresponding to a best match of all the quantities were selected as representative of the operating condition in terms of optical data. The corresponding images are reported in the following figures.

Figure 7 shows pressure and temperature traces in detail for the CADs where the optical results will be shown. The reactant temperatures ahead of the flame were computed according to Equation (1) previously reported. From the data plotted in this figure, it is possible to extract the temperature and pressure corresponding to each image shown in the following. Figure 7 shows that for a given CAD before spark, the stoichiometric and rich cases have progressively lower reactant temperatures compared to the lean cases. This happens because more fuel is injected directly into the combustion chamber, leading both to increase in vaporization cooling and a reduction of $\gamma$. This charge cooling associated with enrichment is well known, and is commonly used for knock suppression at high engine loads $[14,15]$. 

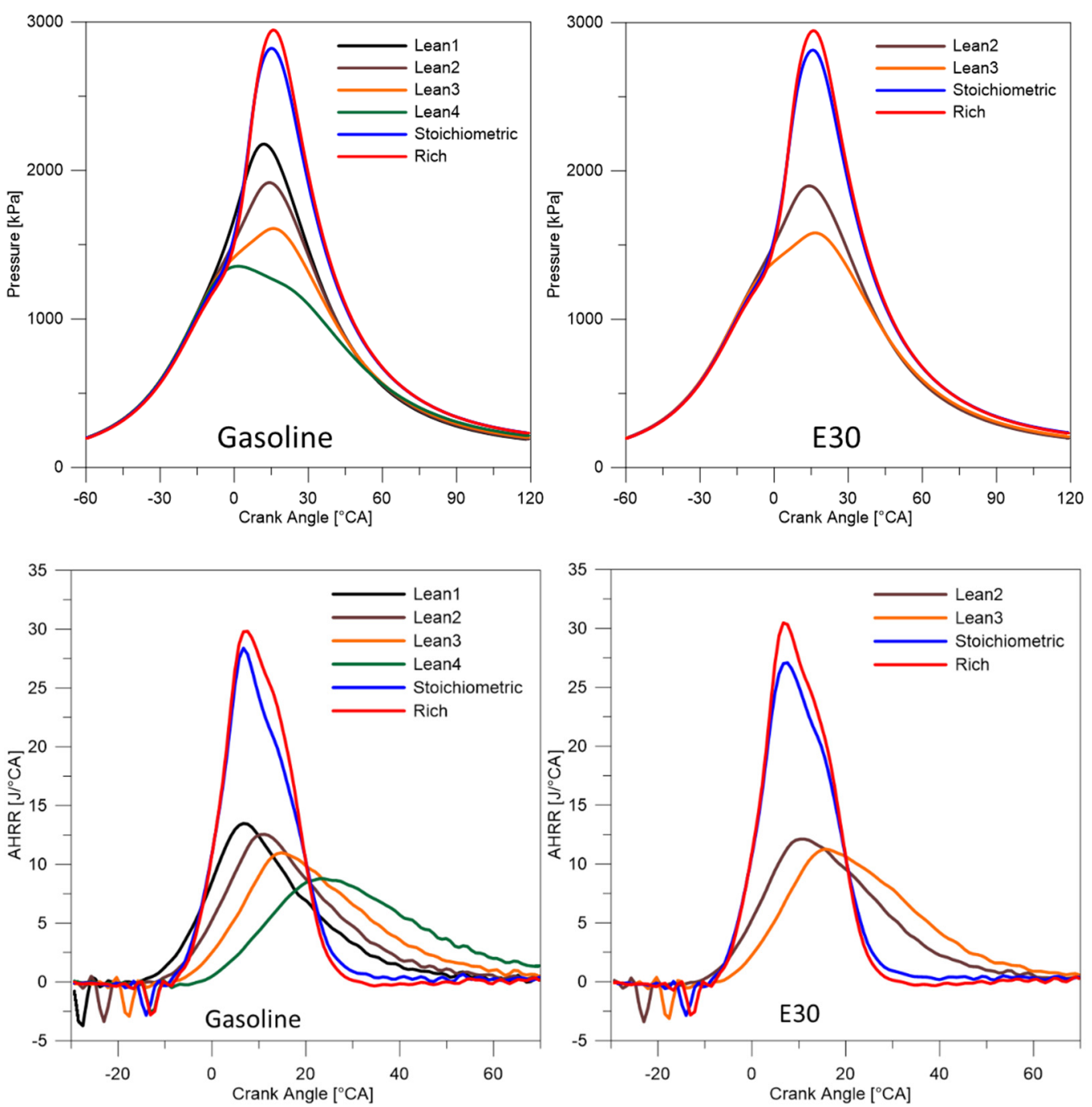

Figure 6. Pressure traces (top) and the rates of heat release (bottom) for gasoline (left) and E30 (right) for all the selected well-mixed conditions. The negative AHRR dips before combustion is caused by noise generated by the initial spark discharge, therefore indicating the spark timing for each case.

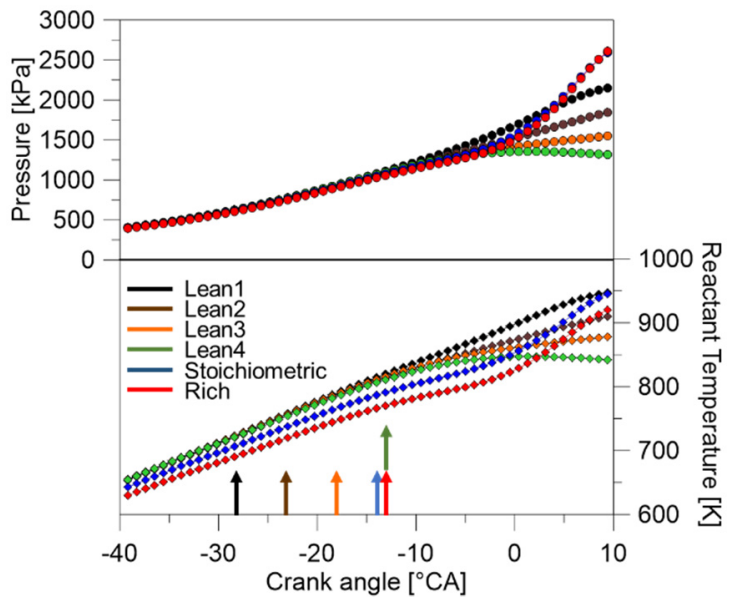

(a)

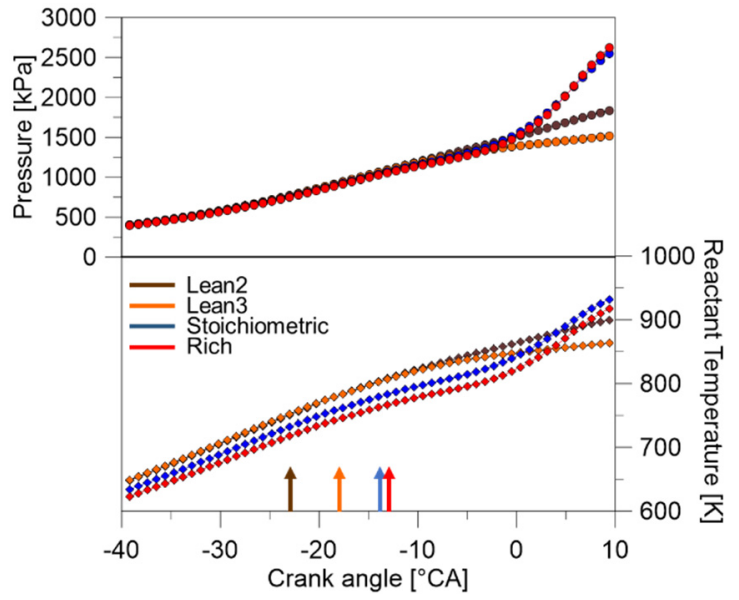

(b)

Figure 7. Reactant temperature and pressure in the first stages of the combustion process for (a) gasoline and (b) E30. The arrows indicate the STs. 
The flame front propagation in lean condition was investigated at different spark timings as reported in Figure 8 for gasoline. Very similar results were obtained for E30, but those are not reported for brevity. The relatively high spark energy of $106 \mathrm{~mJ}$ promotes combustion stability. The high spark energy leads to a relatively long spark duration and spark plasma is often still distinguishable at 12 CAD after ST. The spark plasma stretches out of the gap into the fuel vapor around due to swirl motions in the combustion chamber, as shown at $6 \mathrm{CAD}$ after ST. This allows the spark plasma to ignite the mixture outside the spark gap.

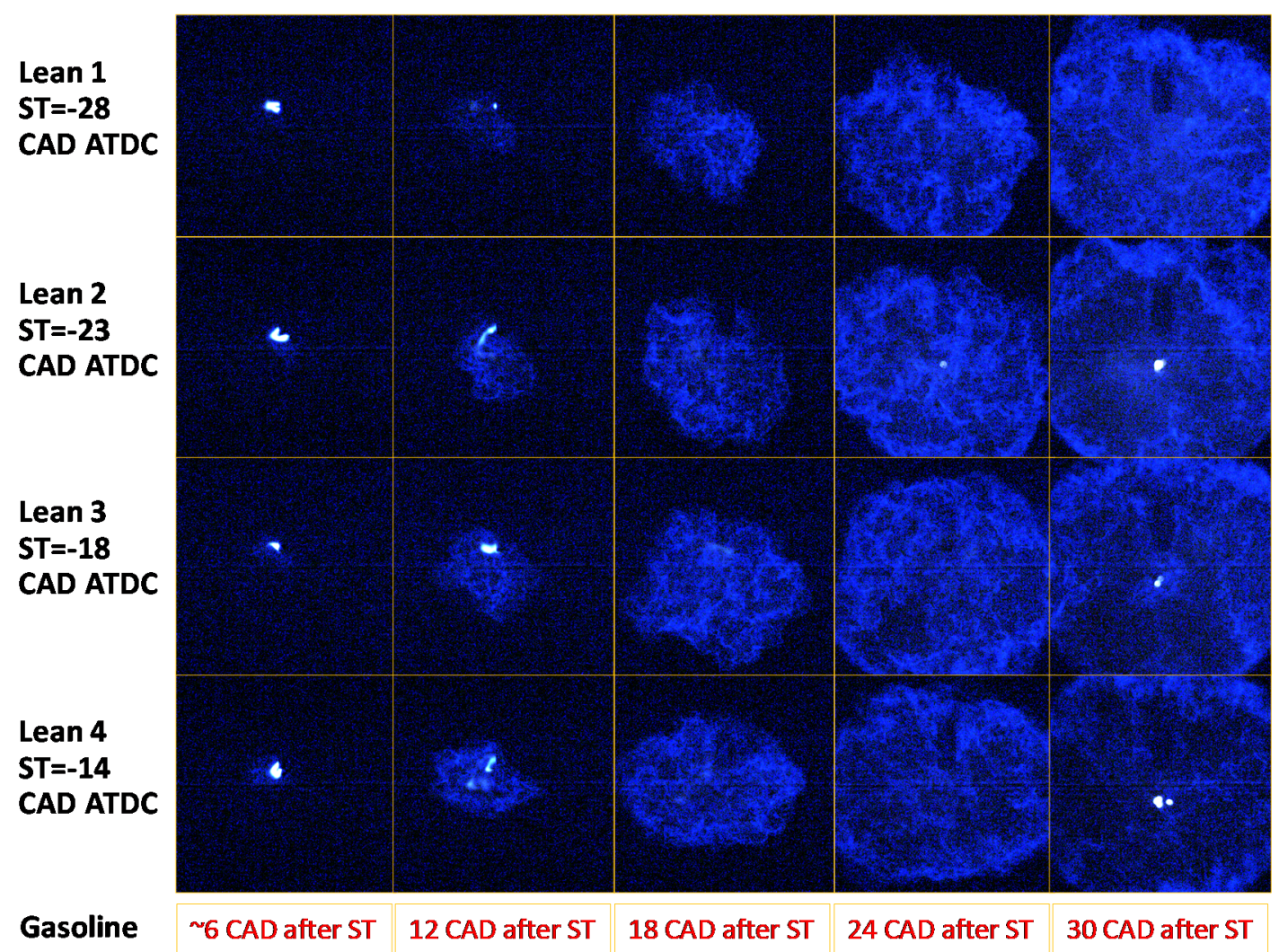

Figure 8. Flame propagation for lean conditions, gasoline fuel, and different spark advances. The gain value for these images was set to 2 .

For all lean conditions, a distinct flame kernel starts developing by 6 CAD after ST in a blue-violet color. The combustion originates from the central spark plug and then it propagates through the chamber with a radial-like behavior. From the acquired images, the evolution of the flame area was calculated using a custom program developed in a LabVIEW environment. For these lean conditions, Figure 9 reports the evolution of the enflamed area against CAD after ST for gasoline (a) and E30 (b), respectively. The area metric is limited by the available aperture of the piston-bowl window.

The early inflammation flame speed increases for a delayed spark timing. This is due to the fact that the reactant temperature is higher for a later ST as a result of the compression heating by the piston. The higher temperature makes the early inflammation faster for Lean 4 compared to Lean 1 despite the increased pressure which tends to slow down the flame [16]. Nevertheless, in this case, the higher initial temperature for Lean 4 overcomes the opposite effects of higher pressure, and results in a faster flame kernel development. Lean 1 condition shows the lowest flame front propagation velocity. Even so, Table 4 shows that Lean 1 exhibits the most stable IMEP $_{n}$. This occurs because an earlier (yet slower) flame development advances the main combustion event, which then takes places closer to TDC and with higher reactant temperatures (cf. temperatures for Lean 1 (950 K) and Lean $4(845 \mathrm{~K})$ at $10 \mathrm{CAD}$ in Figure $7 \mathrm{a})$. 


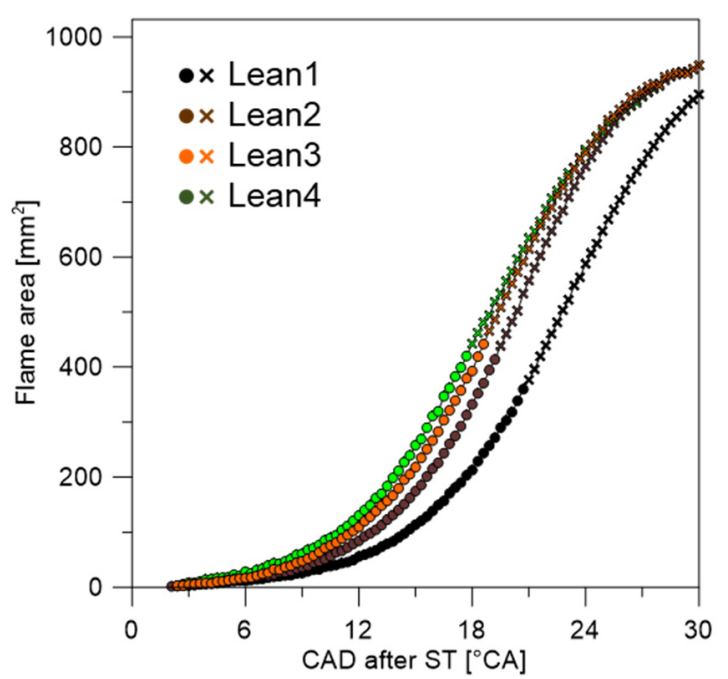

(a)

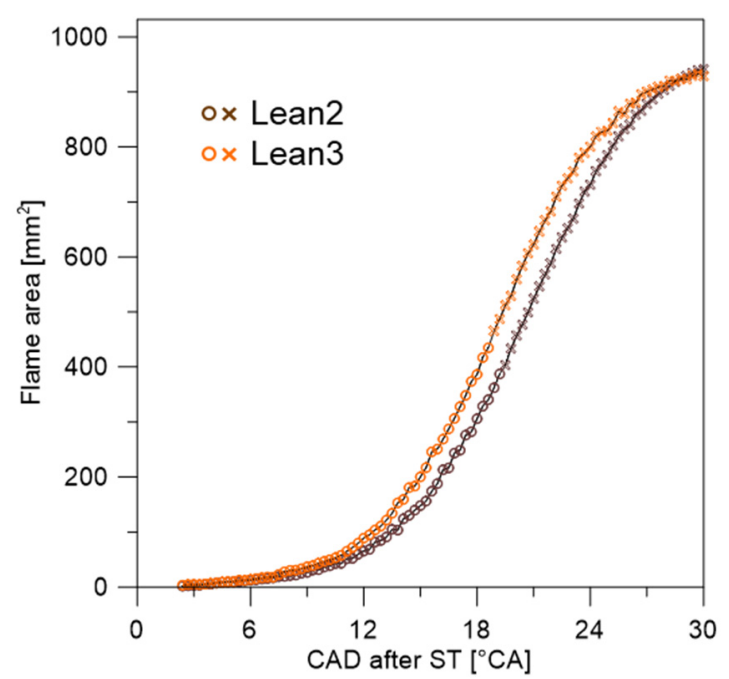

(b)

Figure 9. Flame area for lean conditions, gasoline (a) and E30 (b), at different spark advances. Data points corresponding to the CADs where the flame front has approached the limits of the field of view are represented with crosses.

Figure 10 shows the images of flame propagation for stoichiometric and rich conditions, for gasoline and E30. White balance adjustments were applied to correct image color, enhancing the blue gain. The spark kernel becomes detectable around 2 CAD after ST, then it propagates with a near-circular shape for all the conditions. The initially near-circular flame kernel gradually becomes more wrinkled by turbulence as it grows. The flame corrugation does not show any particular pattern, suggesting that the turbulence in the central part of the combustion chamber is nearly isotropic. This is not surprising given that the combustion takes place a relatively long time after the intake process, giving time for the turbulence to become more uniform [17]. Similar flame coloring was seen for gasoline and E30 but a reduced brightness was detected for the E30 fuel. The lower reactant temperature of E30 may contribute to lower combustion luminosity. For example, at $-5 \mathrm{CAD}$, Figure 7 indicates a $10 \mathrm{~K}$ lower reactant temperature for $\mathrm{E} 30$ at the stoichiometric condition. For more information about the spectral characteristics of the two fuels, please refer to Appendix A.

Based on the flame area, an equivalent flame radius was obtained: it is the radius of a circle having the same area of the flame (Waddell disk). From this, a flame radius growth rate $\mathrm{dr} / \mathrm{dt}$ was calculated for each crank angle interval for each cycle and then averaged over all cycles. The results are reported in Figure 11.

At lean conditions, Figure 11 indicates that the turbulent flame propagation rates were about $50 \%$ lower than for rich and stoichiometric conditions. On average, the rate of flame radius growth increases in a quasi-linear way for all the conditions until it reaches a peak value. In the rich and stoichiometric cases, the peak is observed around 12 CAD after ST. For lean conditions, the location of the peak changes with ST and the Lean 1 case (with the most advanced ST) shows the latest peak. The peak corresponds to the CAD when the flame boundaries start to locally exceed the optically accessible area. The decay in flame velocity after the peak is due to the flame area growth outside the piston window and bears limited quantitative significance.

In Figure 11 the results are reported for gasoline: the radius growth profiles are nearly identical for the two fuels. This confirms that the relatively large differences in octane numbers have no effect for these operating points. This makes sense, as the flame propagation is not controlled by autoignition. 

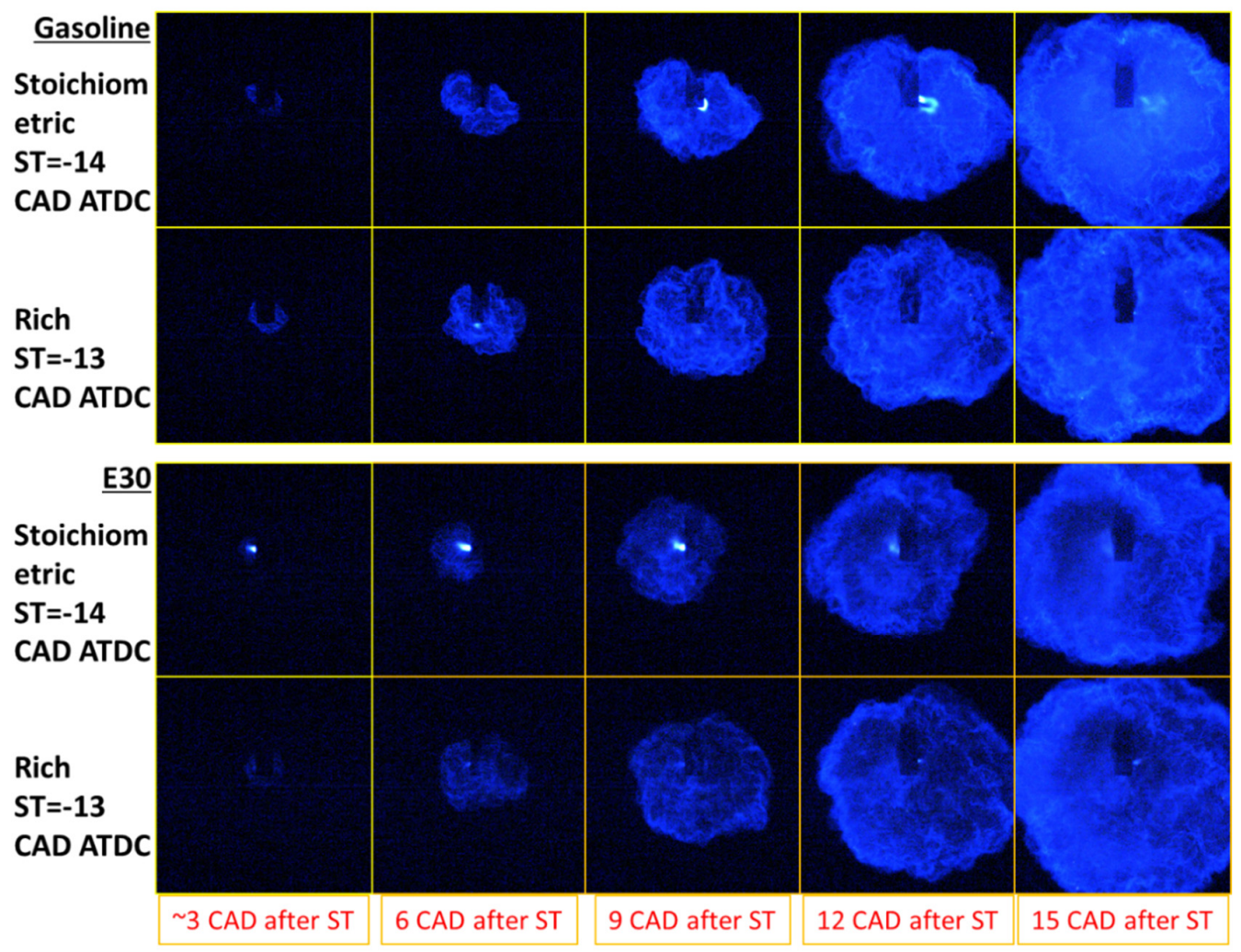

Figure 10. Flame propagation for stoichiometric and rich conditions, for gasoline and E30. The gain value for these images was set to 1 .
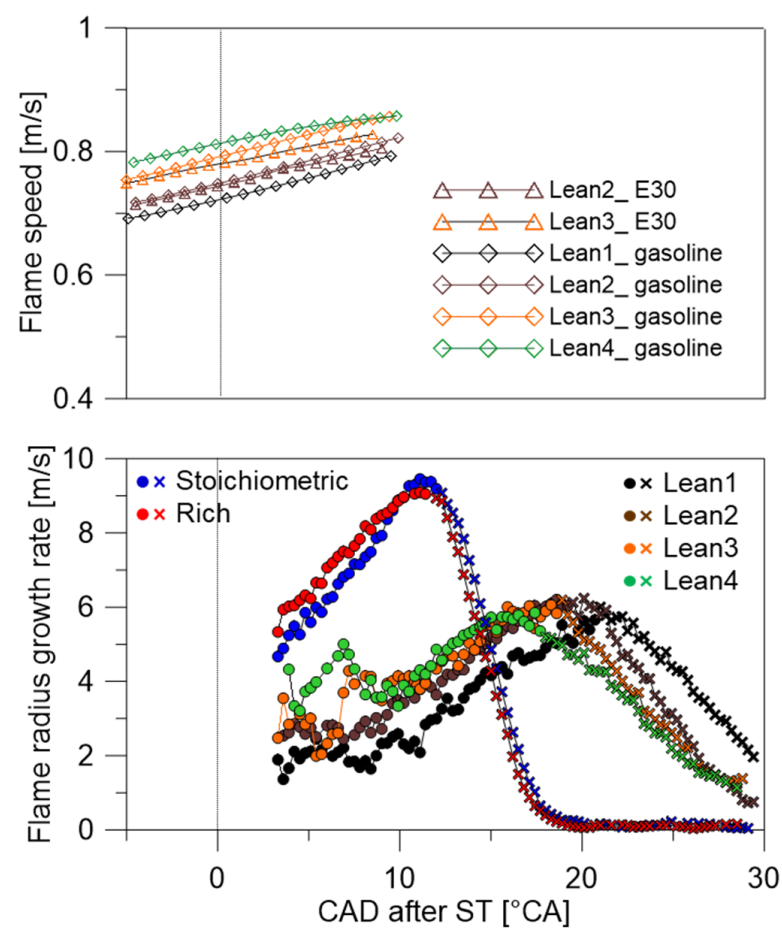

Figure 11. Rate of flame radius growth for gasoline (bottom). Laminar flame speeds are shown (top) for CADs during spark discharge for lean conditions, gasoline, and E30. These were predicted using a detailed chemical-kinetics mechanism $[5,18]$. Data points corresponding to the CADs where the flame front has approached the limits of the field of view are represented with crosses. 
At the top of Figure 11, laminar flame speeds are plotted for the lean condition of gasoline and E30. These results correspond to the in-cylinder conditions leading up to ST and for the duration of the spark discharge. These flame speeds were computed using a detailed chemical-kinetics mechanism, with E30 and gasoline being represented by 5and 4-component surrogate mixtures, respectively $[5,18]$. These results indicate relatively low flame speeds during the spark-discharge period for lean conditions, but also higher flame speed for the more retarded spark timing, as well as a similar behavior for the two fuels. These results are consistent with the well-mixed data from Reference [5] plotted in Figure 1. In Figure 1, E30 and gasoline show very similar trends in terms of IMEP stability. This occurs despite the fact that the ethanol blended into to E30 tends to increase the inherent flame speed. The stronger vaporization cooling of the E30 fuel lowers the reactant temperature, making the flame speed effectively similar for the two fuels. For more insights, the reader is referred to Figure 12 in Reference [5] and Figure 34 in Reference [19].

Figure 12 shows the trajectory of "center of luminosity", i.e., the average position of the total flame area (binary) luminosity. More details about the procedure to obtain this parameter are reported in section "3.1. Postprocessing of the optical data".
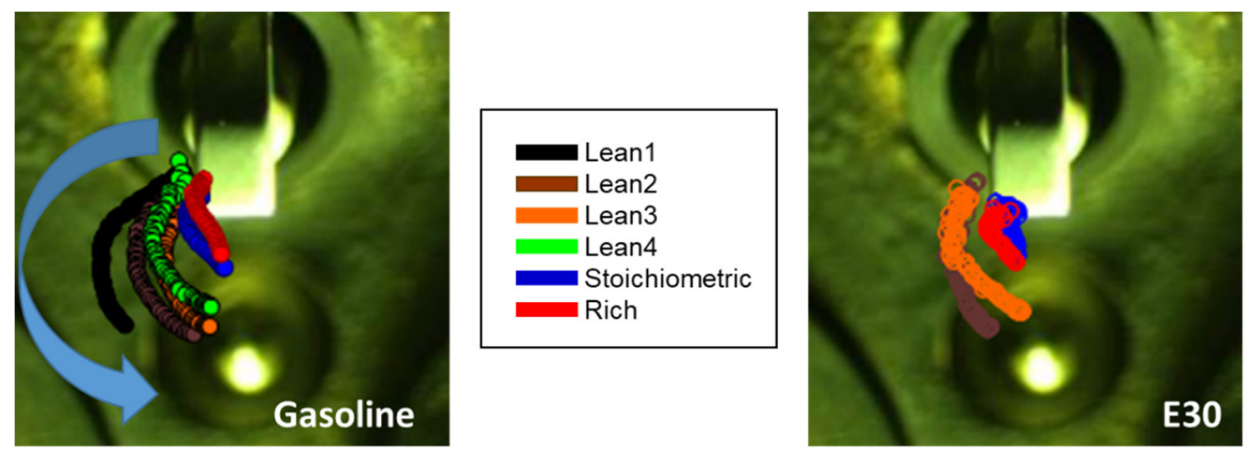

Figure 12. Trajectory of the flame luminosity center for gasoline (left) and E30 (right).

The trajectories of the flame luminosity indicate that the flame propagation is influenced by the swirl motion. As reported in the computational work by Van Dam et al. [20], carried out on the same engine at two different operating conditions (throttled and unthrottled), the flow in the combustion chamber is dominated by strong swirl, with the swirl vortex offset to the lower-right considering the present field of view.

Under lean conditions, the flame propagation is highly influenced by the swirl motion, especially for the earlier ST cases which develop more slowly. Typically, the spark channel is convected to the left from the spark gap by the counterclockwise swirl motion. This is followed by a slow flame propagation, first on the left side of the electrode and then throughout the whole chamber. This happens both for gasoline and E30.

In the stoichiometric and rich conditions, the initial flame propagates in a more "ideal way" with a circular flame front centered more closely on the spark plug. The lower influence of swirl motion on stoichiometric and rich cases is due to the faster flame propagation for these conditions that allows the flame trajectory to be more determined by the turbulent flame speed than by the convective gas motion in the combustion chamber.

\section{Results-Combustion with Partial Fuel Stratification}

Two operating conditions with PFS combustion were selected for this paper and these were introduced in Figure 1. The details are given in the Table 5 . For both conditions, early injections were used to generate a well-mixed lean background, whose equivalence ratio

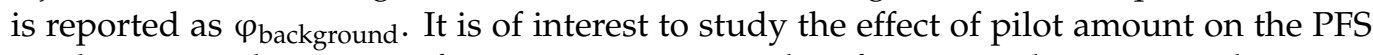
combustion and emissions formation processes. Therefore, two pilot injection durations were compared: $210 \mu$ s for E30 fuel and $330 \mu$ s for gasoline. These operating conditions are referred to as PFS_210 and PFS_330, respectively. Higher stability can be achieved with higher quantities of pilot injection. On the other hand, as speculated in [10], a smaller 
amount of pilot-injection may be able to reduce the amount of $\mathrm{NO}_{\mathrm{x}}$ and soot formed in the enriched combustion in the vicinity of the spark plug. Thus the chosen pilot duration is a compromise between combustion stability and emissions. Nakai et al. [11] examined options for minimizing $\mathrm{NO}_{x}$ production and found that a combination of swirl and split injection can be beneficial. In the current paper, focus is on PFS combustion with a single pilot injection for operation with an intake swirl. It can be noted in Table 5 that the PFS_330 case with gasoline has an early CA50. The combustion phasing is dictated by the need to induce end-gas autoignition (cf. Figure 9 in Reference [10]). The load is lower for the PFS_330 case and the intake temperature is also lower. Both of these factors contribute to the need for an early combustion phasing [10]. The PFS operating point with E30 uses an intake temperature that is rather high. This helps to compensate for the high octane numbers of the splash-blended E30 fuel, enabling a repeatable end-gas autoignition while using a reasonable combustion phasing.

Table 5. Operating conditions for partial fuel stratification combustion analysis. Engine speed is $1000 \mathrm{rpm}$

\begin{tabular}{ccc}
\hline Label & PFS_210 & PFS_330 \\
Fuel & E30 $(-)$ & gasoline \\
$\varphi$ background $(-)$ & 0.51 & 0.45 \\
Intake temperature $\left({ }^{\circ} \mathrm{C}\right)$ & 100 & 0.36 \\
Intake pressure $(\mathrm{kPa})$ & 110 & 52 \\
Spark (CAD ATDC) & -27 & 101 \\
Start of early injection $(\mathrm{CAD}$ ATDC) & -310 & -31 \\
Early injection duration $(\mu \mathrm{s})$ & 475 & -330 \\
Number of early injections & 3 & 480 \\
Start of pilot injection $(\mathrm{CAD}$ ATDC) & -30 & 2 \\
Pilot injection duration $(\mu \mathrm{s})$ & 210 & -34 \\
Pilot mass injected $(\mathrm{mg})$ & 0.84 & 330 \\
Start of pilot injection, actual (CAD ATDC) & -28 & 3.4 \\
IMEP $(\mathrm{kPa})$ & 545 & -32 \\
IMEP nd $_{\mathrm{n}}(\mathrm{kPa})$ & 7.73 & 419 \\
COV of IMEP $(\%)$ & 1.42 & 5.80 \\
CAD 10\% MFB & -14.22 & 1.38 \\
CAD 50\% MFB & 1.83 & -21.98 \\
CAD 90\% MFB & 16.70 & -9.63 \\
\hline
\end{tabular}

\subsection{Injection Visualization}

PFS operating strategies are highly dependent on pilot fuel injection during the late compression stroke. Before the combustion experiments, spray imaging was carried out over wide ranges of conditions to better understand the general spray behavior. Due to space constrains, here the focus will only be on the two injection durations used for the two PFS combustion experiments. An injection timing of $-30 \mathrm{CAD}$ was selected from the larger data set since it corresponds exactly to the PFS_210 case with E30 and is reasonably close to the PFS_330 case with gasoline. This spray imaging provides a better understanding of the fuel-air mixture formation. The presented evolution of the pilot injection events can also serve as validation data for CFD models. Having the same electronic start of injection in the engine cycle ( -30 CAD ATDC), the sprays evolve at the same ambient pressure and temperature for the two injection durations and thus there is no difference in evaporation behavior induced by the environment. It should be noted that no early injections were performed, so these pilot injections penetrate into air that does not contain any fuel vapor. This may change the rate of vaporization somewhat compared to the actual PFS operating points. Furthermore, here the focus is on the E30 fuel.

Figure 13 shows the spray visualization from $0.2 \mathrm{CAD}$ after $\mathrm{SOI}_{\mathrm{a}}$ from bottom and lateral fields of view for E30 and the two selected injection durations. Eight individual fuel jets can be identified clearly from the bottom field of view. From the lateral side, four jets 
are visible, each of them is the result of the overlapping of two jets in row, this is expected to induce a slight overestimation of the average penetration length from this point of view. At the engine speed of interest here $(1000 \mathrm{r} / \mathrm{min})$, spray imaging shows the first appearance of a liquid phase at the nozzle tip around 2 CAD from the start of electrical actuation. The time when the fuel starts to exit from the outlet of the nozzle holes is defined as "start of pilot injection-actual" $\left(\mathrm{SOI}_{\mathrm{a}}\right)$. The image data show that the $\mathrm{SOI}_{\mathrm{a}}$ occurs $0.1 \mathrm{CAD}$ earlier for the $330 \mu$ injection duration case.
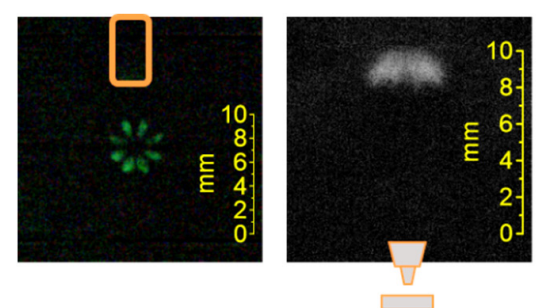

SOla+0.2 CAD
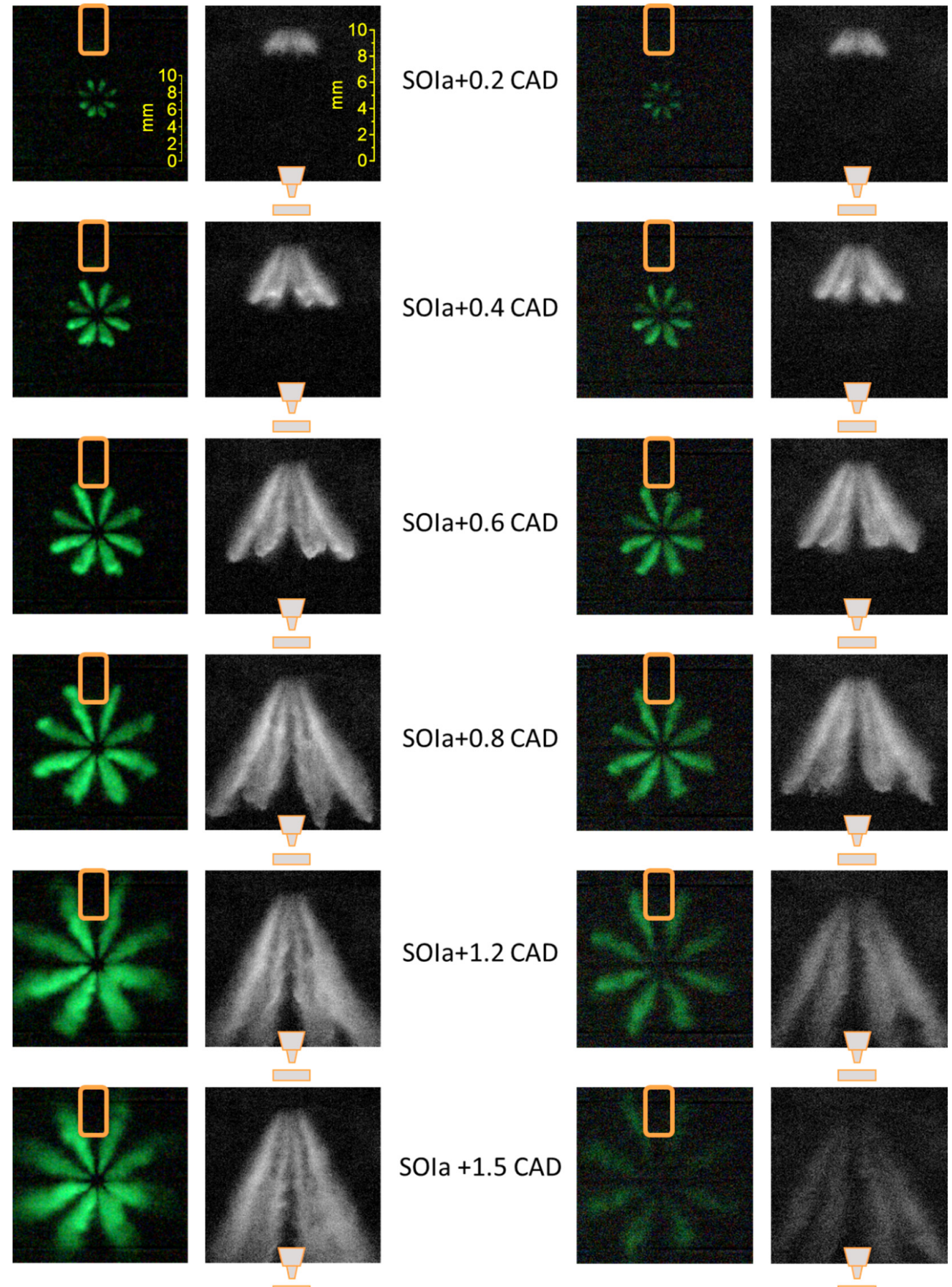

Dur: $330 \mu \mathrm{s}$
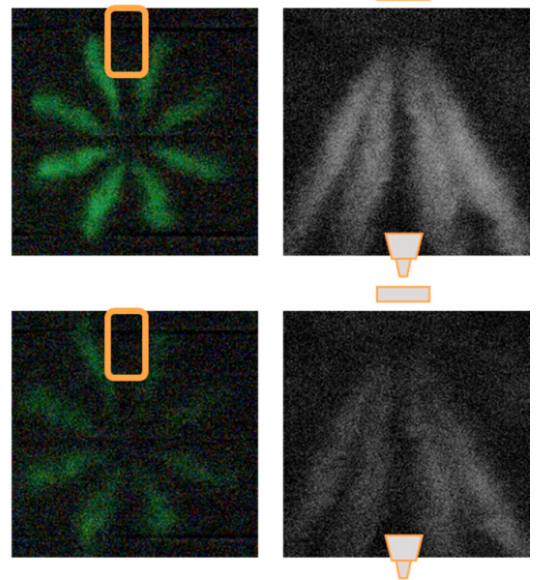

Dur: $210 \mu \mathrm{s}$

Figure 13. Spray visualization from 0.2 CAD after the start of injection (actual) from bottom and lateral field of view for E30. The outline of the spark electrode is reported in each image. 
The high temporal resolution of the spray imaging allows a visualization of the effects of air-fuel interaction during the spray evolution. In agreement with the results reported in [21], the air-fuel spray interface is exposed to significant shear forces. These forces generate "recirculation zones", i.e., vortices that become wider as distance form nozzle tip increases, and form "fishbone structures" due to the dispersion of slow-moving small droplets. These can be clearly seen at $1.2 \mathrm{CAD}$ after $\mathrm{SOI}_{\mathrm{a}}$ for $330 \mu$ s injection duration, when the spray is fully developed.

To quantitatively characterize the spray, $2 \mathrm{~d}$ projection of liquid penetration length is measured based on the procedure previously described. For each visible jet, the liquid penetration length is estimated as mean value over several consecutive image sequences along the directions indicated in Figure 14 (left), the results are reported in Figure 14 (right) as color dots together with the average value for all the jets.
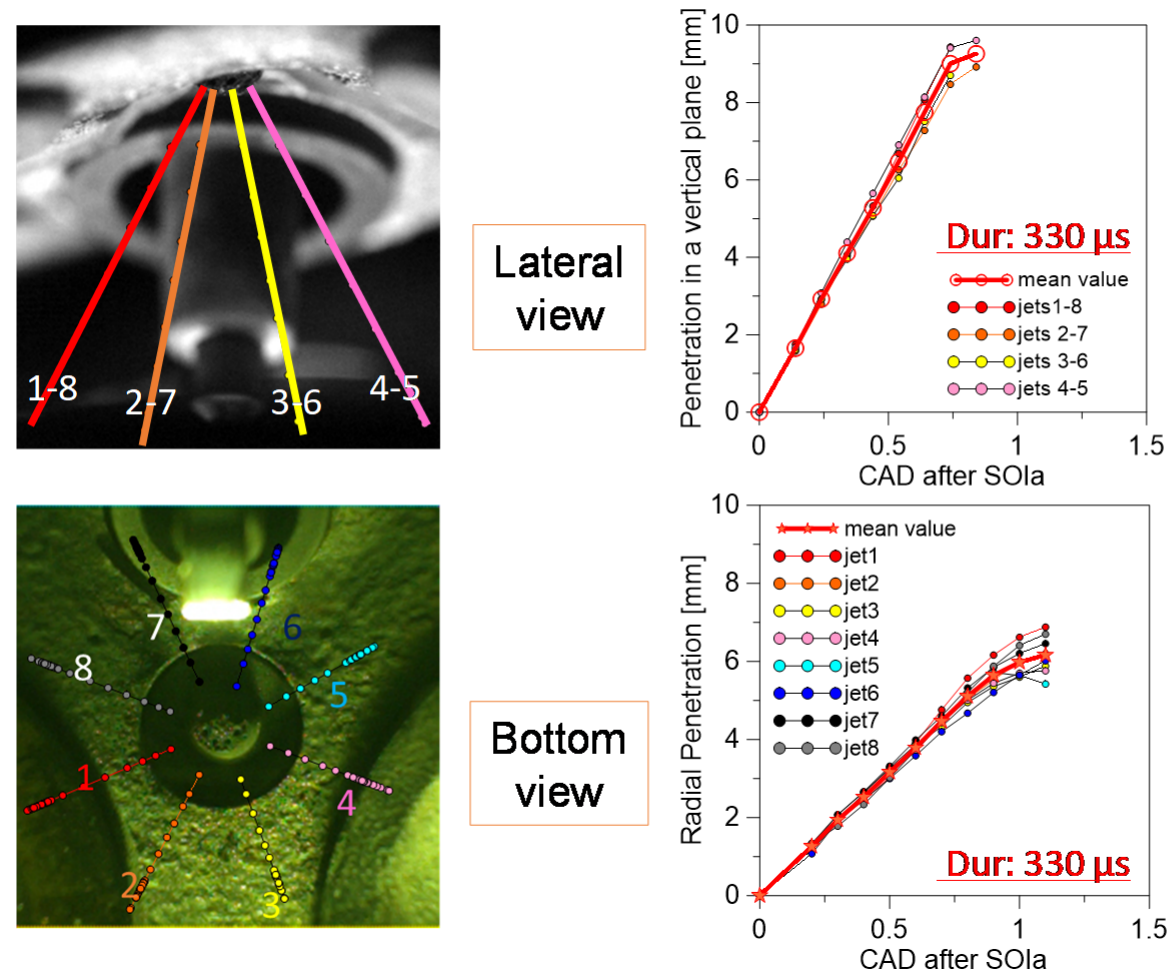
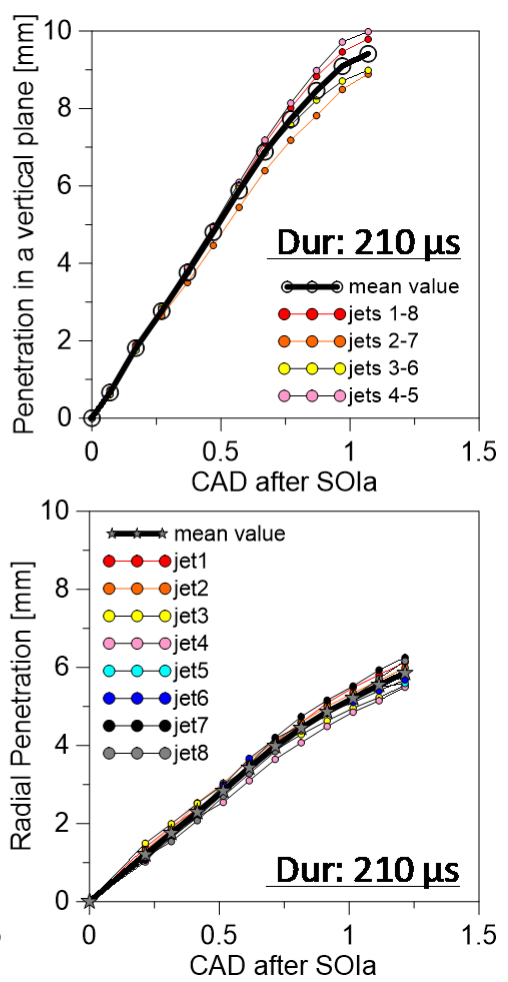

Figure 14. Directions for fuel spray penetration evaluation (left) and penetration length (right) obtained for all visible jets.

The actual penetration length in $3 \mathrm{~d}$ space was computed based on the lateral view for each of the four pairs of sprays: $1-8,2-7,3-6,4-5$. The mathematical average of the radial penetration for each pair was computed and combined with the average of the penetration in the vertical plane for the same pair. The results are reported in Figure 15, which shows the mean penetration for both conditions and the values corresponding to each pair of jets.

It can be observed that the penetration increases with time after the start of injection, but also that the penetration rate is somewhat lower during the latter part of the of the spray development. Overall it can be noted that a higher injection duration leads to faster liquid penetration of spray. This behavior is due to the different fueling rates measured for the two injection durations. The difference among the two conditions can be observed clearly from both fields of view.

In order to calculate the time needed by the liquid fuel tip to travel from the nozzle exit to the spark-gap area, Image J (TM) software was used to calculate the mean value of Mie-scattered light intensity in two selected regions corresponding to the spark gap. The aim of this is to understand the fuel "distribution" near the spark plug during the injection process at the start of spark discharge. The procedure was described in the section "3.1. Postprocessing of the optical data" and the results are reported in Figure 16 together with 
the arrows indicating the $\mathrm{CAD}$ corresponding to beginning of the spark event for both conditions: 1.2 and 1.1 CAD after SOI for PFS_330 and PFS_210, respectively.

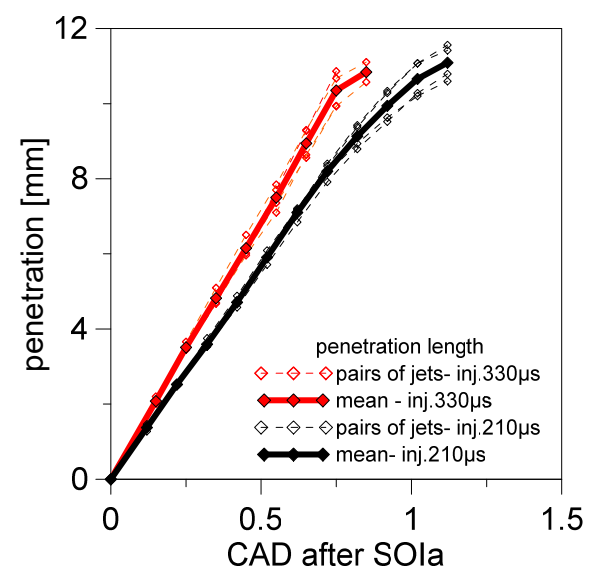

Figure 15. Actual mean penetration length for the two injection durations.

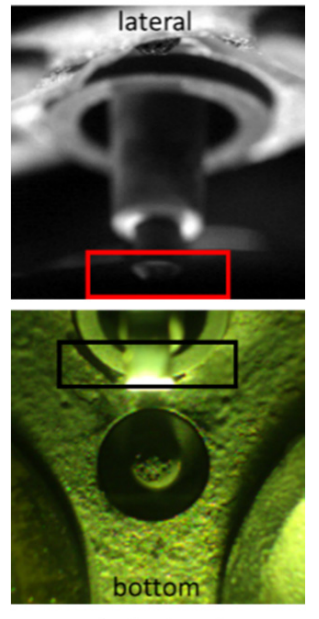

selected regions

(a)
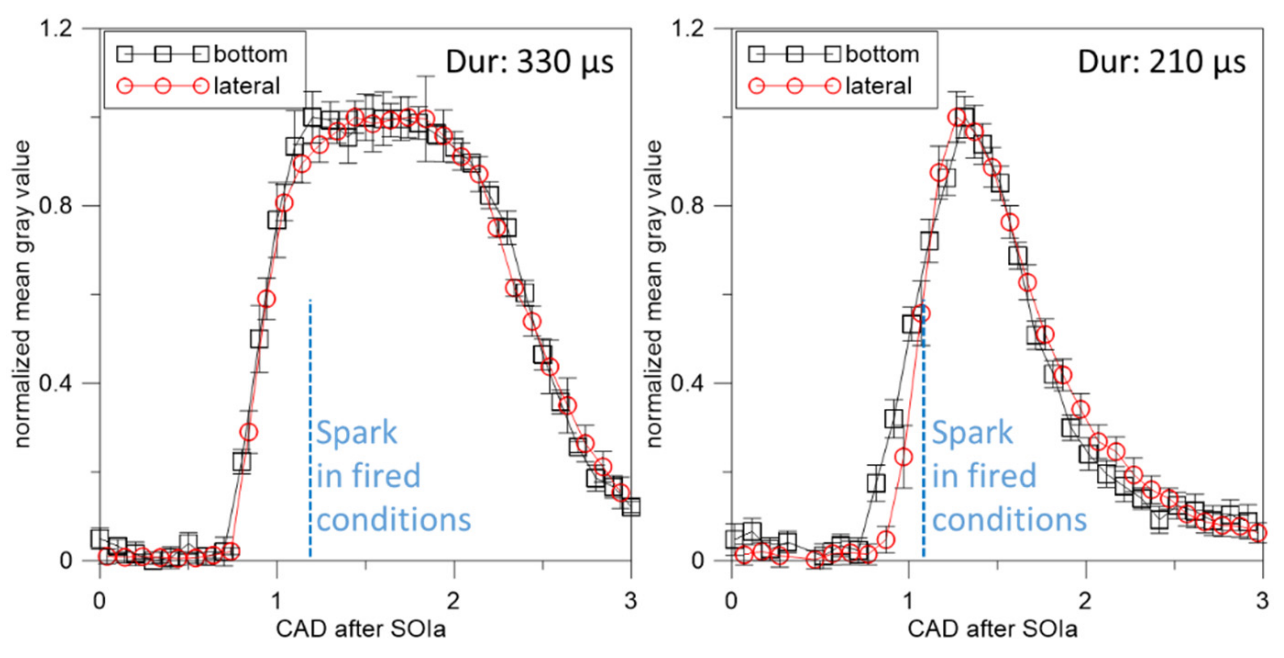

(b)

Figure 16. Regions of the combustion chamber (a) corresponding to the spark gap used to calculate the mean gray value of Mie-scattered light intensity (b), averaged over all sequences.

It is evident that at the ST, the spray is almost completely developed in the spark gap region for $330 \mu \mathrm{s}$ duration and not in the case of $210 \mu \mathrm{s}$. Anyway, this parameter did not affect the kernel flammability since the spark plasma duration is sustained for a long time during PFS operation (around 7 CAD, as determined from high-speed images) well after the initial kernel growth.

Each data point is an average of 30 images with the standard deviation indicated by the error bars: for both durations, the repeatability of the injection phenomenon is good.

\subsection{PFS Combustion Visualization}

A representative single cycle was selected for each PFS operating condition, based on matching the heat-release profile to the corresponding ensemble-averaged profile. The following images correspond to these selected cycles. Figure 17 reports the visualization of the pilot injection in PFS conditions with 0.3 CAD image resolution from the first observable liquid spray until the kernel ignition for gasoline with an injection duration of $330 \mu$ s and E30 with an injection duration of $210 \mu \mathrm{s}$. Consistent with the spray imaging that has a $0.1 \mathrm{CAD}$ image resolution, the first images of the sequences in Figure 17 correspond to 
0.2 CAD after $\mathrm{SOI}_{\mathrm{a}}$ for gasoline and 0.1 CAD after $\mathrm{SOI}_{\mathrm{a}}$ for E30. Hence, the first frame shows a slightly longer penetration for the gasoline case.

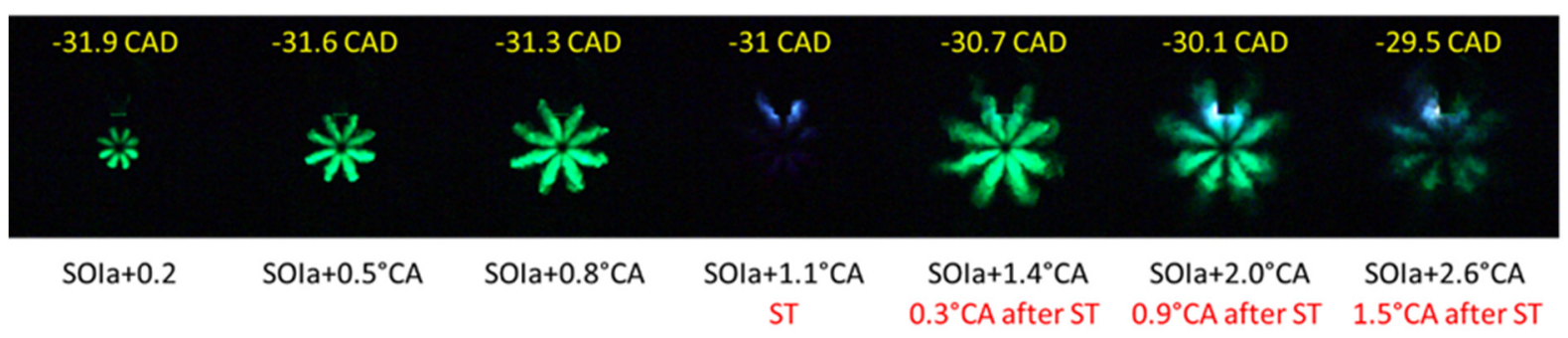

Dur: $330 \mu \mathrm{s}$, gasoline.

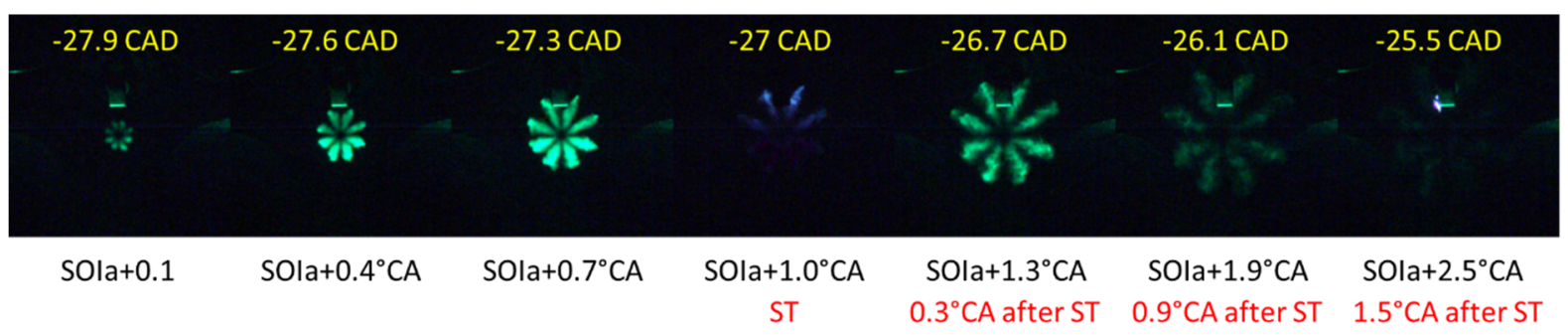

Dur: $210 \mu \mathrm{s}, \mathrm{E} 30$.

Figure 17. Pilot visualization from the first observable liquid spray until the kernel ignition.

For both conditions, the spark discharge starts while liquid fuel is clearly present near the spark-plug gap. In agreement with the results obtained with the "injection only" visualization, when the mixture starts igniting, at 1.5 CAD after ST (around 2.5 CAD after $\mathrm{SOI}_{\mathrm{a}}$ ), the fuel jet structure is still observable in the case of injection duration of 330 us, consequently light scattering from the spark discharge can be detected in the spray at the left side of the spark plug. In the case of 210 us, the liquid structure has almost disappeared. While not presented here for brevity, a very stretched spark discharge channel could be observed for both conditions, due to strong local in-cylinder flow field and long spark duration.

Figure 18 reports the flame propagation in PFS conditions and the corresponding AHRR. The yellow dots on the AHRR traces correspond to the CADs of the presented images. The AHRR profiles are distinctly different for the two conditions. This occurs because of the large difference in the relative fuel-energy contribution from the pilot injection. For the PFS_210 case, $0.84 \mathrm{mg}$ E30 is supplied with the pilot and this corresponds to $4.0 \%$ of the total fueling amount per cycle $(21.2 \mathrm{mg}$ E30). In contrast, for the PFS_330 case, $3.4 \mathrm{mg}$ gasoline is supplied with the pilot, corresponding to $20.6 \%$ of the total fueling amount (16.5 mg gasoline). However, for both PFS cases the combustion ends with an AHRR peak that corresponds to the end-gas autoignition. This occurs despite differences in fuel type and engine load because the combustion phasing was adjusted for each case to achieve moderately strong end-gas autoignition that ensures complete combustion and an acceptably short combustion duration [10]. 


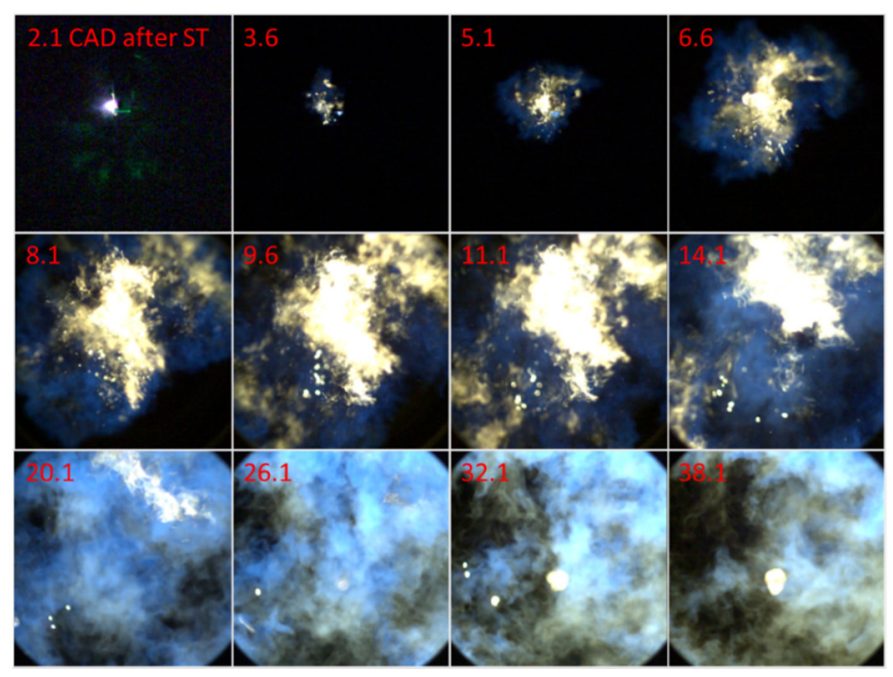

(a)

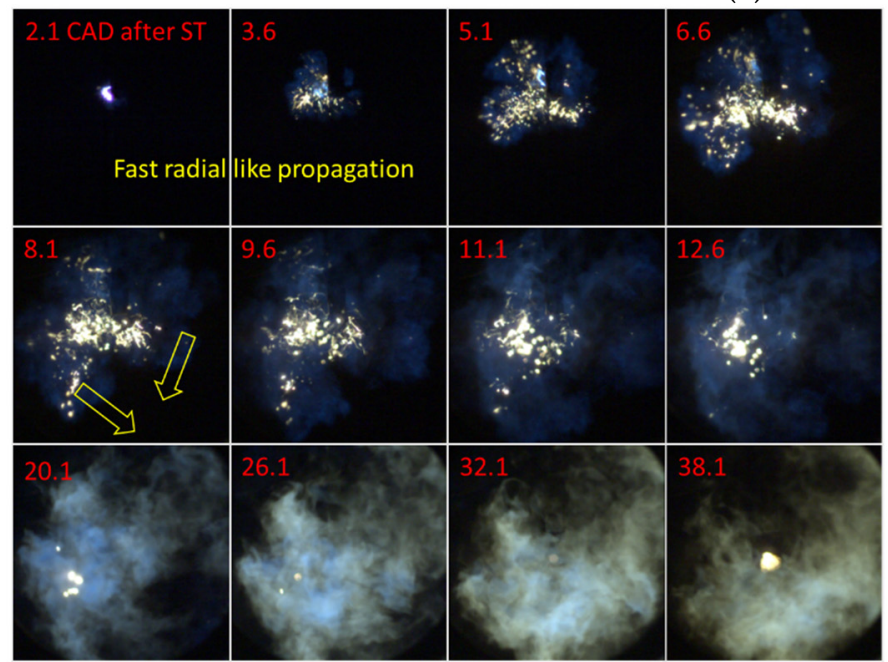

(b)
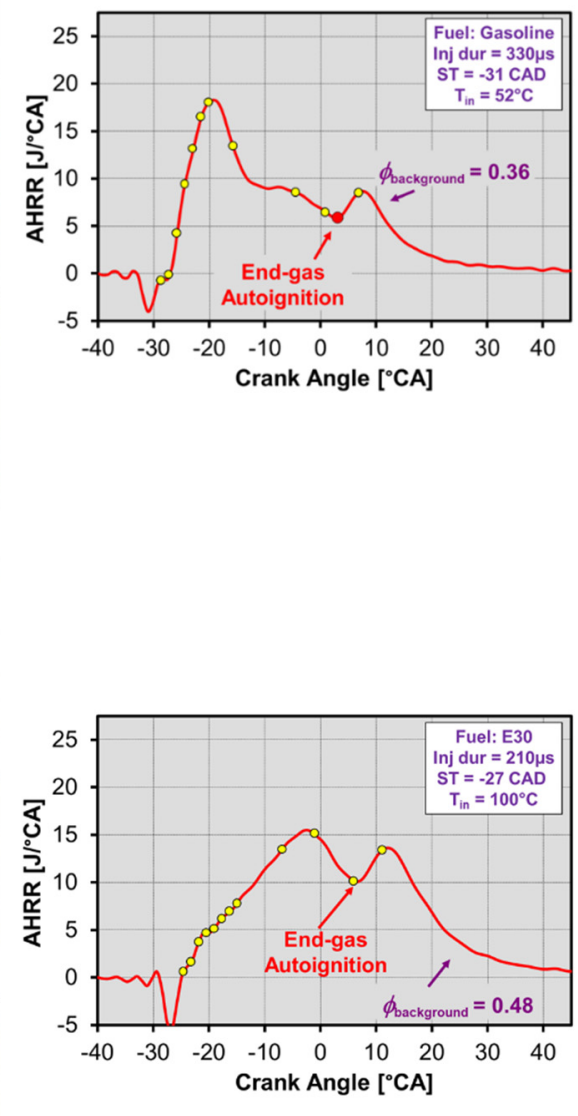

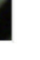

Figure 18. Flame propagation in PFS conditions: pilot injection duration (a) $330 \mu \mathrm{s}$ and (b) $210 \mu \mathrm{s}$. The yellow dots on the AHRR trace correspond to the CADs where the images were acquired. In the first image of (a) the gain is 4 times the gain used in the other images, to highlight the presence of liquid scattering.

For PFS_330 with gasoline the combustion AHRR in Figure 18 shows a 3-stage mode due to the relatively large pilot injection, which induces an early strong AHRR peak. During this first stage, spark-ignited stratified charge combustion takes place. The spark plasma is still present at $2.1^{\circ}$ after ST and it stretches out from the gap igniting the flame kernel, which is quite apparent at $3.6^{\circ}$ after ST, although the first small kernel can be seen at $1.5^{\circ}$ after ST, i.e., in the last image of the sequence reported in Figure 17. The subsequent combustion process is characterized by a blue flame, different from the wellmixed combustion previously discussed. Instead of an initially spherical flame kernel that progressively becomes more wrinkled by turbulence when it expands, the early flame in this case is not perfectly spherical and highly wrinkled. The blue flame is accompanied by yellow diffusive flames due to combustion in rich zones (potentially near liquid fuel) present in the combustion chamber. It is hypothesized that the rich zones are partially due to a delayed or incomplete evaporation of the fuel injected by the pilot, and partially due to liquid films deposited on the spark plug. Even for this case with the longer pilot duration of $330 \mu \mathrm{s}$, it is unlikely that pilot-injected fuel is deposited on to piston surfaces. Closely related studies in the same engine show that no piston-top wall wetting occurs for a pilot injection duration shorter than $400 \mu \mathrm{s}[22,23]$. The observed presence of diffusive flames is related to the formation of soot in the combustion chamber as reported in [24]. However, 
these rich zones appear to burn mostly to completion during the first part of the combustion process, with a low impact on the exhaust soot emission level (cf. Figure 22 in [10]). The non-spherical form of the kernel is likely caused by local variations of equivalence ratio and enthalpy due to droplet vaporization and heat losses to surfaces (e.g., electrodes), as well as flow effects.

Following the development of the initial flame fronts, the second combustion stage is initially dominated by propagation of blue flames due to combustion of mostly well-mixed mixtures. These flames propagate rapidly and move outside the field of view by 14.1 CAD after ST. After this point, the visible flames are not well resolved and appear "hazy". It is assumed that the late-cycle luminosity in the central part of the combustion chamber is dominated by thermal emissions of the compressed and heated combustion products.

The third stage of the combustion process is the compression autoignition stage in well-mixed ultra-lean end-gas, manifested as a peak on the AHRR trace around 8 CAD after TDC (near 38.1 CAD after ST). At this timing, basically all of the end-gas reactants are found outside the field of view, and this makes it impossible to visualize the end-gas autoignition process.

For the PFS_210 E30 case, the combustion AHRR in Figure 18 shows a 2-stage mode, since the smaller pilot injection does not induce an early AHRR peak. After the kernel inception, the flame propagates with a radial-like behavior and an almost circular shape for a very short time. For PFS_210, there is not a clear evidence of liquid fuel at the start of kernel growth as the liquid fuel appears vaporizes quickly. Even so, the blue flame typical of well-mixed combustion is coupled with a yellow flame caused by rich combustion. However, for PFS_210, these flames are less extensive compared to PFS_330. After a few CADs, at around 4 CAD after ST, the flame propagation is no longer circular and isotropic. Instead, it slows down and follows "preferred" directions, presumably determined by the local conditions (T, $\varphi$ and turbulence) that favor the spread of the flame. In the particular cycle shown in Figure 18b, two different flame fronts propagating in the direction indicated with yellow arrows could be recognized. Flame fronts propagate outside the field of view by 12 CAD after ST and the flame spread is relatively slow in the outer parts of the piston-bowl area. End-gas autoignition cannot be studied in this configuration.

As shown in Figure 19, the luminosity trajectories for PFS_330 and PFS_210 are very similar. Compared with the results reported for well-mixed conditions, it is clear that they are not analogous to the trajectories of the lean well-mixed conditions. As previously reported, in lean well mixed conditions, the flame trajectory was highly influenced by the swirl motion. The PFS conditions show a very fast kernel propagation and the flame is not convected to the left in the combustion chamber as observed for lean well-mixed conditions. The high turbulent flame speed of the enriched reactants reduces the convective effects of swirl. It is also possible that the flow induced by the pilot injection masks any effects of the intake-generated swirl. The flame trajectory in the PFS lean condition is more similar to rich and stoichiometric well-mixed conditions: an almost straight line from the spark plug side (11 o'clock location) towards the center of the chamber.

The importance of the ignition and early flame kernel growth period were recently reviewed [25]: cycle-to-cycle variability of the early flame kernel makes the flame during the main part of the combustion event experience different in temperature and pressure, as well as different in turbulence, amount of fuel-air mixing, and flow in and out of the piston bowl. To quantify the ignition stability of these PFS conditions, Figure 20 shows 2D-probability maps (PDFs) of flame location obtained using 70 individual images at 6 CAD after ST for PFS_330 and PFS_210, corresponding to -25 CAD and -21 CAD ATDC respectively. The probability maps are created through Image J software, by using Li's Minimum Cross Entropy thresholding method [26] to binarize the individual cycle flames. The PDFs quantify the probability of observing the flame at a particular location and CAD. Figure 20 shows that statistically there are substantial differences in the flame development for the two cases. First of all, at this timing, 6 CAD after ST, the flame is more extended for the PFS_330 case. This is expected based on its substantially larger pilot mass of fuel. 
In particular, the contour for $90 \%$ probability is much larger for the PFS_330 case. The shapes of the probability contours are also different. The PFS_330 case shows fairly circular contours, whereas the PFS_210 case shows a more complex structure, which indicates that the flame early development has some preferred directions. This is consistent with the observations from Figure $18 b$.

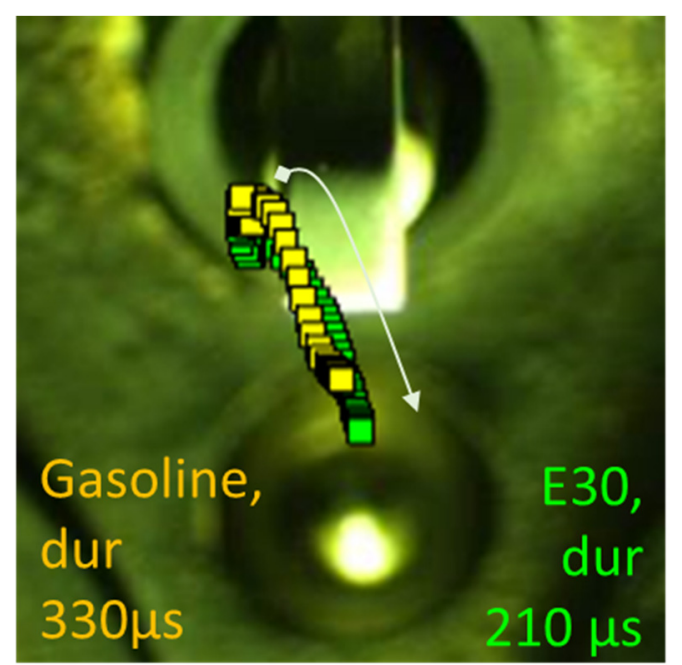

Figure 19. Trajectory of the flame luminosity center for PFS_330 and PFS_210.
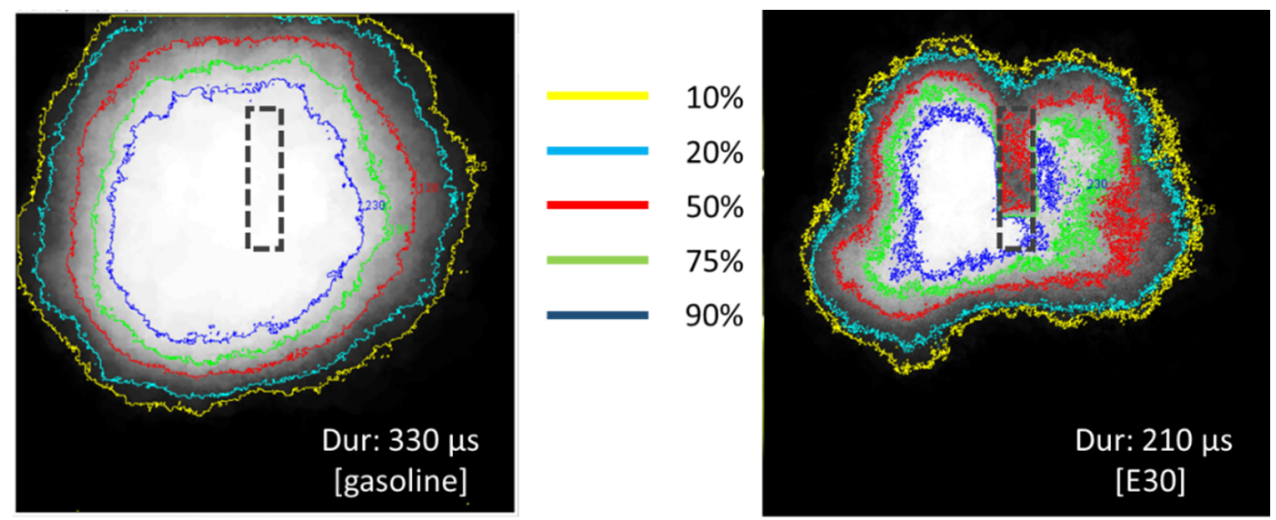

Figure 20. Flame variability at 6 CAD after ST in PFS conditions, the grey dotted lines indicate the spark plug position.

To summarize, Figure 21 reports the flame area evolution and the rate of flame spread for PFS in comparison with well-mixed conditions. It should be noted that the results for well-mixed conditions are only reported for gasoline since the radius-growth profiles are nearly identical for the two fuels at these operating conditions. As previously discussed, stoichiometric and rich well-mixed cases show a higher flame radius growth rate at the very beginning of the combustion process compared to lean conditions.

For PFS conditions, the initial flame spread is very fast for both cases even compared to the rich well-mixed case, suggesting that the fast flame propagation for PFS is not only caused by the locally richer mixtures near the spark plug. As qualitatively observed by the flame visualization, in PFS_210 the flame front propagation is very fast for a short time, and after around 4 CADs after ST it slows down. PFS_330 is characterized by even higher flame propagation speeds for a longer time. A hypothesis is that this acceleration of the flame development for the PFS cases is caused by enhanced flow velocities and elevated turbulence level that the pilot injection induces. The four lean cases show that a later ST leads to an acceleration of the early flame development due to the higher compressed-gas temperatures later in the compression stroke (cf. Figure 7). The stoichiometric and rich 
cases both have late ST, so both benefit from the added compression heating. In contrast, the PFS cases have early ST and therefore benefit less from compression heating. In addition, it can be noted that the rich and stoichiometric cases bracket the equivalence ratio where peak flame speeds are encountered for gasoline and gasoline-ethanol blends $(\varphi=1.1)$, see Figure 34 in [19] and Figure 9 in [16]. These observations strengthen the proposed hypothesis that pilot-induced flow and turbulence substantially contribute to the observed strong enhancement of the early flame development for the two PFS cases. However, it should be noted that this comparison of the early flame development is performed at an engine speed of $1000 \mathrm{rpm}$. It is suggested that future work includes higher engine speeds since the increased in-cylinder flows may affect PFS and well-mixed operation differently.
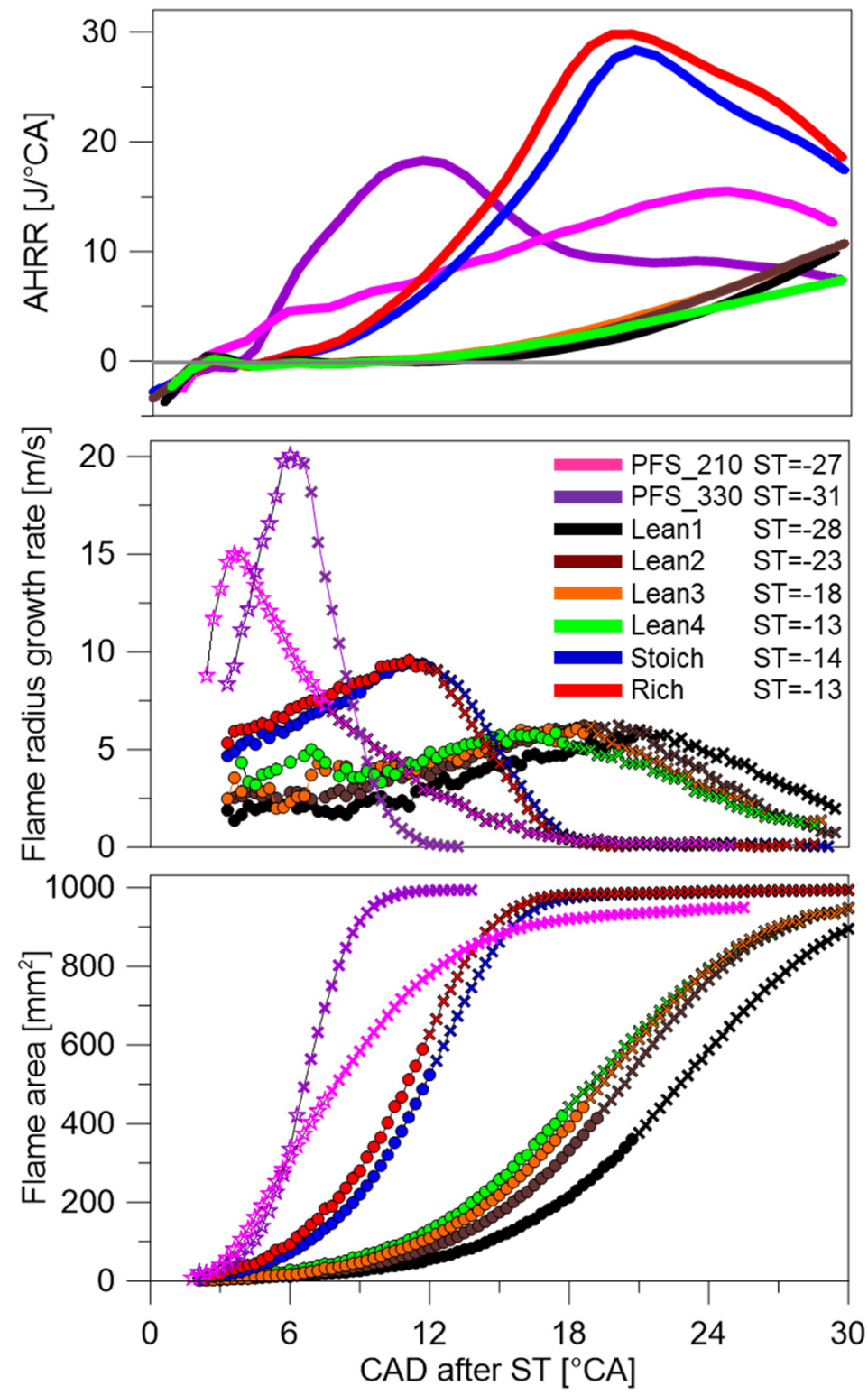

Figure 21. AHRR, rate of flame radius growth and flame area evolution, for well-mixed combustion (with gasoline) and PFS (for gasoline: PFS_330 and E30: PFS_210). Data points corresponding to the CADs where the flame front has approached the limits of the field of view, are represented with crosses. 


\section{Conclusions}

The investigations presented here provided new insights into a partial fuel stratification combustion strategy that can be used to stabilize lean SI operation. The following conclusions are drawn:

1. The different spray evolution in terms of penetration and liquid permanence for the two pilot injection durations examined here (330 $\mu$ s and $210 \mu \mathrm{s})$ strongly influences the flame kernel inception and propagation.

2. The PFS combustion process is characterized by a non-spherical and highly wrinkled blue flame, different from a spherical well-mixed flame kernel which progressively becomes more wrinkled by turbulence when it expands. The blue flame in both PFS cases is coupled with yellow diffusive flames due to the combustion of rich zones near the spark plug.

3. The initial flame spread for both PFS cases is very fast when compared to any of the well-mixed cases (lean, stoichiometric, and rich), suggesting that the flame propagation for PFS is enhanced by enhanced turbulence induced by the pilot injection.

4. PFS with a pilot duration of $210 \mu$ s using E30 fuel (PFS_210) and $330 \mu$ s using gasoline (PFS_330) show some differences in terms of shapes of the flame front (more irregular for PFS_210) and in terms of extension of rich diffusive flames (lower for PFS_210 with E30), but both show high repeatability.

Additionally, the following information was gained for well-mixed combustion.

1. The combustion originates from the central spark plug and then the blue-violet flame propagates through the chamber with a radial like behavior.

2. Stoichiometric and rich conditions show flame propagation rates about $50 \%$ higher than lean conditions. For lean conditions, the early inflammation flame speed increases for a delayed spark timing due to the higher compressed-gas temperature, which more than fully compensates for the reduction of flame speed due to the higher gas pressure.

3. E30 and gasoline fuels show very similar characteristics regarding flame shape, color, and propagation behavior. The relatively large differences in octane numbers between the two fuels have no effect for these operating points where the flame propagation is not controlled by autoignition.

The quantitative results reported in this paper can serve as an experimental database for validation of CFD modeling approaches used to optimize innovative combustion strategies in DISI engines.

Supplementary Materials: The following are available online at https:/ /www.mdpi.com/1996-107 3/14/2/396/s1, Video S1: PFS combustion process for E30 and pilot injection duration $210 \mu \mathrm{s}$.

Author Contributions: Conceptualization, C.T. and M.S.; Data curation, C.T. and M.S.; Formal analysis, C.T.; Funding acquisition, M.S.; Investigation, C.T. and M.S.; Project administration, M.S.; Resources, M.S.; Supervision, M.S.; Visualization, C.T.; Writing—original draft, C.T.; Writingreview and editing, C.T. and M.S. All authors have read and agreed to the published version of the manuscript.

Funding: The activity of Cinzia Tornatore was partially supported by a Fulbright Scholar grant. The experimental work was performed at the Combustion Research Facility, Sandia National Laboratories, Livermore, CA. This research was conducted as part of the Co-Optimization of Fuels \& Engines (Co-Optima) project sponsored by the U.S. Department of Energy (DOE) Office of Energy Efficiency and Renewable Energy (EERE), Bioenergy Technologies and Vehicle Technologies Offices. Sandia National Laboratories is a multi-mission laboratory managed and operated by National Technology and Engineering Solutions of Sandia, LLC., a wholly owned subsidiary of Honeywell International, Inc., for the U.S. Department of Energy's National Nuclear Security Administration under contract DE-NA0003525.

Data Availability Statement: The data presented in this study are available on request from the corresponding author. 
Acknowledgments: The authors would like to thank Wei Zeng and Zongiie Hu for help with the experiments and constructive technical discussions. The authors would also like to thank Alberto Garcia, Gary Hubbard, Keith Penney, Chris Carlen and Tim Gilbertson for their dedicated support of the DISI laboratory. James MacDonald and Namho Kim provided valuable feedback on the manuscript.

Conflicts of Interest: The authors declare no conflict of interest.

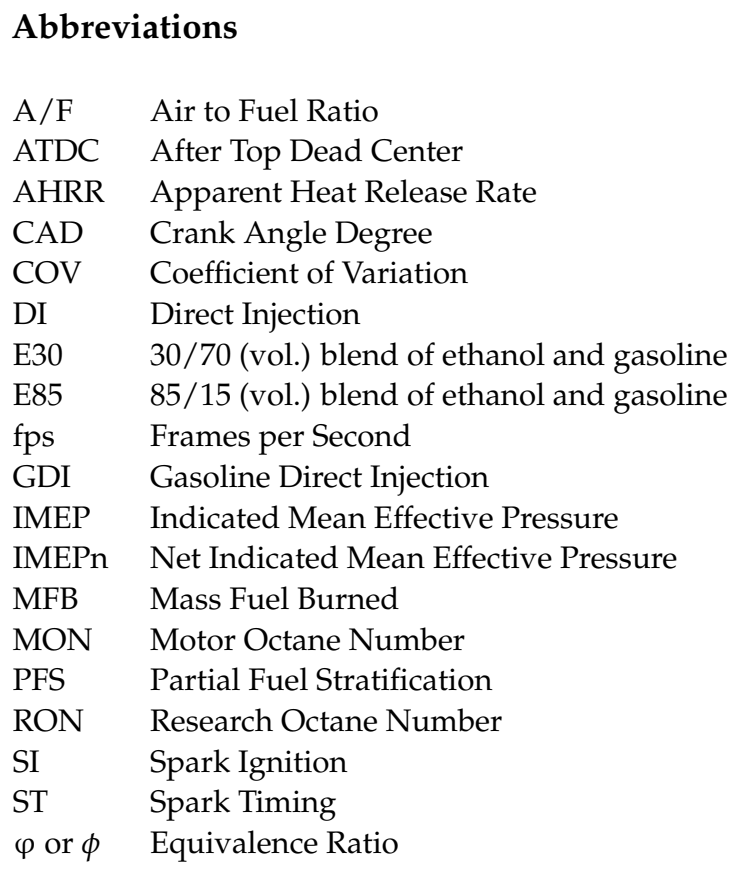

\section{Appendix A}

The presence of an $\mathrm{OH}$ group in ethanol can influence the combustion chemistry compared to paraffin hydrocarbons. The oxygen atom in the alcohol molecule changes the electronic structure, therefore $\mathrm{C}-\mathrm{H}$ bonds strengths are different than their values for structurally similar non-oxygenated hydrocarbons [27]. For this reason, the initial chemical pathways of ethanol combustion can be different compared to non-oxygenate gasoline.

UV-visible natural emission spectroscopy is a useful optical diagnostic to obtain information about the excited chemical species that simultaneously are present in the combustion chamber. Therefore, spectroscopy was applied in the present work to understand if $30 \%$ ethanol added to gasoline alters the chemistry of the combustion process sufficiently that the natural emission spectrum also changes.

Spectroscopic experiments were conducted using the experimental setup shown in Figure Ala. The radiation from the combustion chamber was focused by a UV lens into the entrance slit (open at $250 \mu \mathrm{m}$ ) of an Acton SP2300 spectrometer with $300 \mathrm{~mm}$ focal length and 150 groove/mm grating (central wavelength $350 \mathrm{~nm}$ ). The spectrometer was coupled with an intensified CCD (Charge-Coupled Device) camera: PI-MAX3 (Princeton Instruments) with an array size of $1024 \times 1024$ pixels, pixel size of $13 \times 13 \mu \mathrm{m}$ and Gen III Filmless intensifier type. The exposure time was fixed at $166.66 \mu \mathrm{s}$, corresponding to $1 \mathrm{CAD}$ at $1000 \mathrm{rpm}$. Spectroscopic investigations were carried out in the central region of the combustion chamber as shown in Figure A1b. 


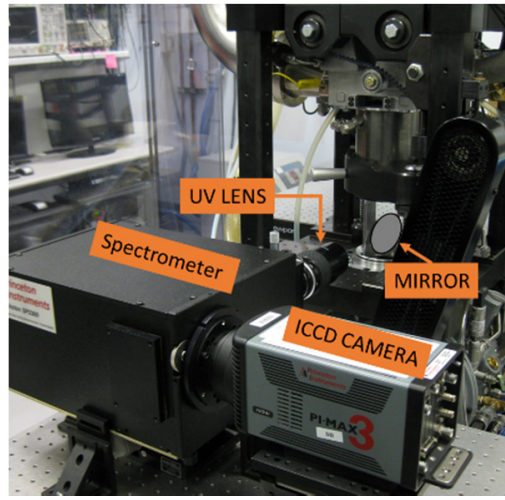

(a)

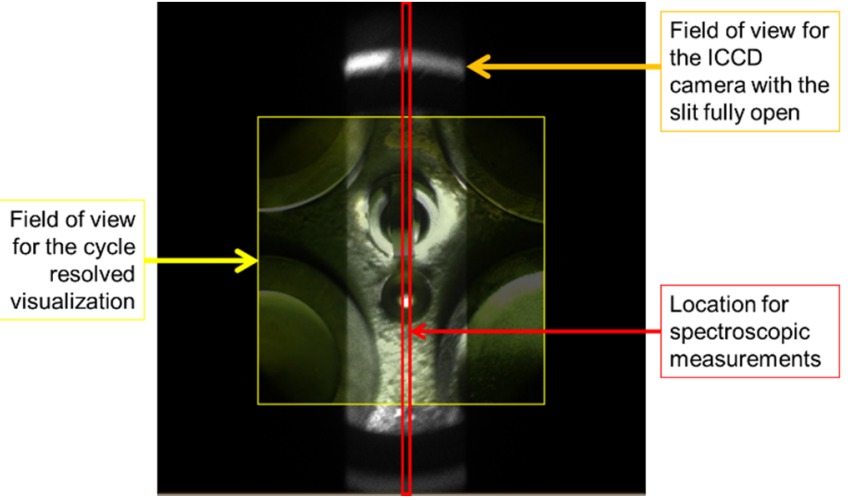

(b)

Figure A1. (a) Experimental setup for spectroscopic measurements; (b) Location for spectroscopic measurements compared with the field of view from ICCD with a fully open slit and from CMOS camera (cf. Figure 3d).

Spectroscopic measurements were performed for 3 well-mixed mode conditions reported in Table 4: Lean 2, stoichiometric, and rich, for gasoline and E30. The acquisition was carried out at selected CADs characterized by a flame that is well developed but still away from the chamber walls and the edge of the field of view. The CADs selected are shown in Table A1, pressure and temperature levels were comparable for all the conditions. A flame image representative of the timing of spectrum acquisition was selected for each of the conditions and is reported in Figure A2.

Table A1. Operating conditions for spectroscopic measurements (details of the engine parameters are reported in Table 4).

\begin{tabular}{cccc}
\hline Condition Label & Fuel & ST (CAD ATDC) & $\begin{array}{c}\text { Timing of Spectra } \\
\text { Acquisitions (CAD ATDC) }\end{array}$ \\
\hline lean2 & Gasoline/E30 & -23 & -6 \\
stoichiometric & Gasoline/E30 & -13 & -4 \\
rich & Gasoline/E30 & -14 & -3 \\
\hline
\end{tabular}
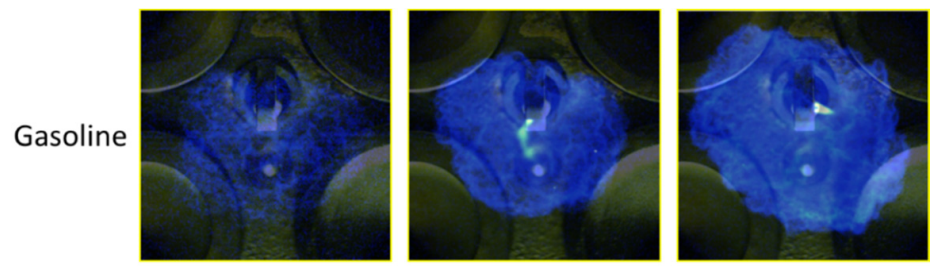

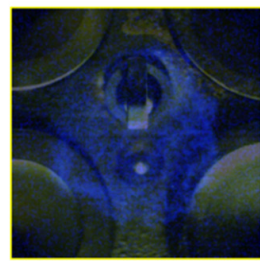

lean2

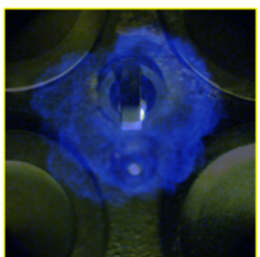

stoichiometric

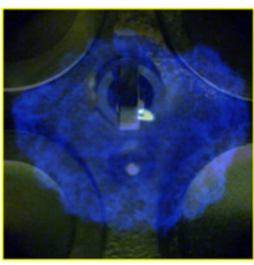

rich

Figure A2. Flame images representative of the timing of spectra acquisition at the CADs reported in Table A1.

For each condition (lean, stoichiometric, and rich) 40 frames were acquired at the selected CAD. For each frame, the flame front location was identified and the spectrum corresponding to the flame front was computed averaging 64 adjacent spectra to enhance the signal-to-noise ratio. Then an averaging was performed over all the 40 frames and a 
mean spectrum corresponding to the flame front was obtained. The results are shown in Figure A3.

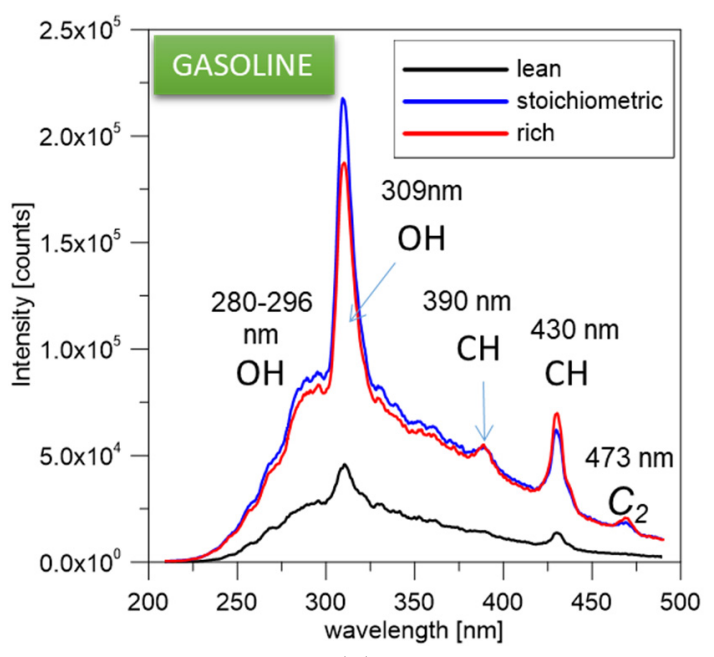

(a)

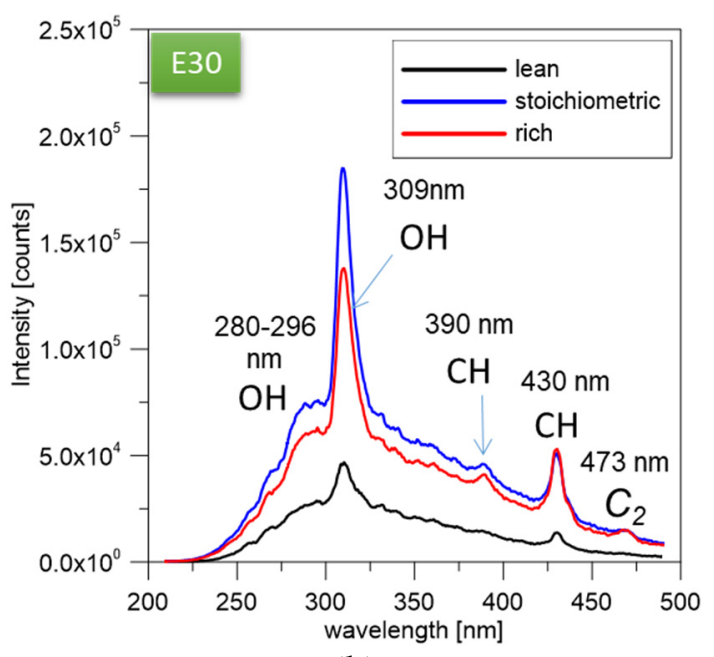

(b)

Figure A3. UV-VIS flame emission spectra detected at the selected CAD for: (a) Gasoline; (b) E30.

For both fuels and each $\varphi$, spectra were featured by $\mathrm{OH}^{*}$ indicating an occurring oxidation. In reaction mechanism models of gasoline and ethanol the $\mathrm{OH}$ radical is involved in the initial decomposition of the fuel molecule, it is produced during oxidation as a product of chain branching and propagating reactions and is a reactant in exothermic chain propagating reactions [28].

Since the work of Dieke and Crosswhite [29] the $\mathrm{OH}^{*}$ flame emission spectrum is known and well-investigated, it is mainly composed by band systems at $309 \mathrm{~nm}$ (highest), between $280-296 \mathrm{~nm}$ and between $314-325 \mathrm{~nm}$, all due to $(\mathrm{A}-\mathrm{X})$ transition. In the spectra reported here, the peak corresponding to $309 \mathrm{~nm}$ is extremely evident and it can be noted that its absolute height is highest for stoichiometric conditions. A lower intensity band between 280 and $296 \mathrm{~nm}$ can also be detected.

In addition to $\mathrm{OH}^{*}, \mathrm{CH}^{*}$ emission bands can be resolved: the most intense one is the (A-X) band with the peak at $430 \mathrm{~nm}$. A weaker band can be observed from 387 to $491 \mathrm{~nm}$ with the local maximum at $390 \mathrm{~nm}$ due to the (B-X) transition [30].

Diatomic carbon, $\mathrm{C}_{2}{ }^{*}$, typically shows the so called Swan bands [31] at $473 \mathrm{~nm}$, $516 \mathrm{~nm}$, and $563 \mathrm{~nm}$. In the wavelength range selected for this paper, the emission at $473 \mathrm{~nm}$ was observed.

$\mathrm{CH}^{*}$ and $\mathrm{C}_{2}{ }^{*}$ are strongly connected to the carbon concentration during the combustion process and thus to the air to fuel ratio. Accordingly, these bands appear more intense for rich cases and very low in lean conditions, for both fuels.

The formaldehyde $(\mathrm{HCOH})$ Emeleus cool flame band system and formyl radical (HCO) Vaidya hydrocarbon system are overlapped and placed under $\mathrm{OH}^{*}$ and $\mathrm{CH}^{*}$ bands. The first one is positioned between 340 and $520 \mathrm{~nm}$, with its highest peak around $390 \mathrm{~nm}$, the second one between 250 and $410 \mathrm{~nm}$. These two species are directly correlated to $\mathrm{CH}^{*}$ production through the decomposition of the HCO radical and the hydrogen peroxide formation $[32,33]$.

The two fuels showed similar spectral features and intensities, indicating that in this operating conditions, there are no evident differences among the chemical pathways followed by the two fuels at the beginning of the combustion process. This is consistent with the very similar lean instability limit shown in Figure 1, as well as the very similar AHRR (Figure 6) and flame spread (Figure 9). 


\section{Appendix B}

Figure 17 shows that the AHRR profiles are different for the two PFS combustion cases. To better understand the relative contributions to the global AHRR from the three different stages of combustion, this Appendix B presents a Wiebe-based analysis. The Wiebe function has seen widespread use as an approximation to experimental heat-release rates [34], partly owing to its combination of simplicity and versatility. A slightly modified equation from [34] is used for this analysis, as shown in Equation (A1).

$$
\mathrm{HRR}_{\text {Wiebe }}=\mathrm{A} \frac{6.908(m+1)}{\text { Comb_Dur }}\left(\frac{\text { CADrelSOC }}{\text { Comb_Dur }}\right)^{m} e^{-6.908\left(\frac{\text { CADrelsoC }}{\text { Comb_Dur }}\right)^{m+1}}
$$

Here, $\mathrm{A}$ is a magnitude-scaling factor, $\mathrm{m}$ is a shape factor, CADrelSOC is the crank angle relative to start of combustion (for each particular Wiebe function), and Comb_Dur is the combustion duration. As discussed in Reference [34], complex combustion scenarios can be approximated with the use of several Wiebe functions. PFS combustion is characterized by three distinct combustion events associated with the pilot-enriched region, deflagration through the lean main charge, and end-gas autoignition. Therefore, it is natural to mimic the PFS AHRR rate with a combination of three separate Wiebe functions.

$$
\mathrm{HRR}_{\text {Wiebe-Total }}=\mathrm{HRR}_{\text {Wiebe-1 }}+\mathrm{HRR}_{\text {Wiebe-2 }}+\mathrm{HRR}_{\text {Wiebe-3 }}
$$

Figure A4a,c show that three Wiebe functions can fairly well approximate the experimentally derived AHRR for both PFS cases. The largest discrepancies can be found during the main lean deflagration phase.
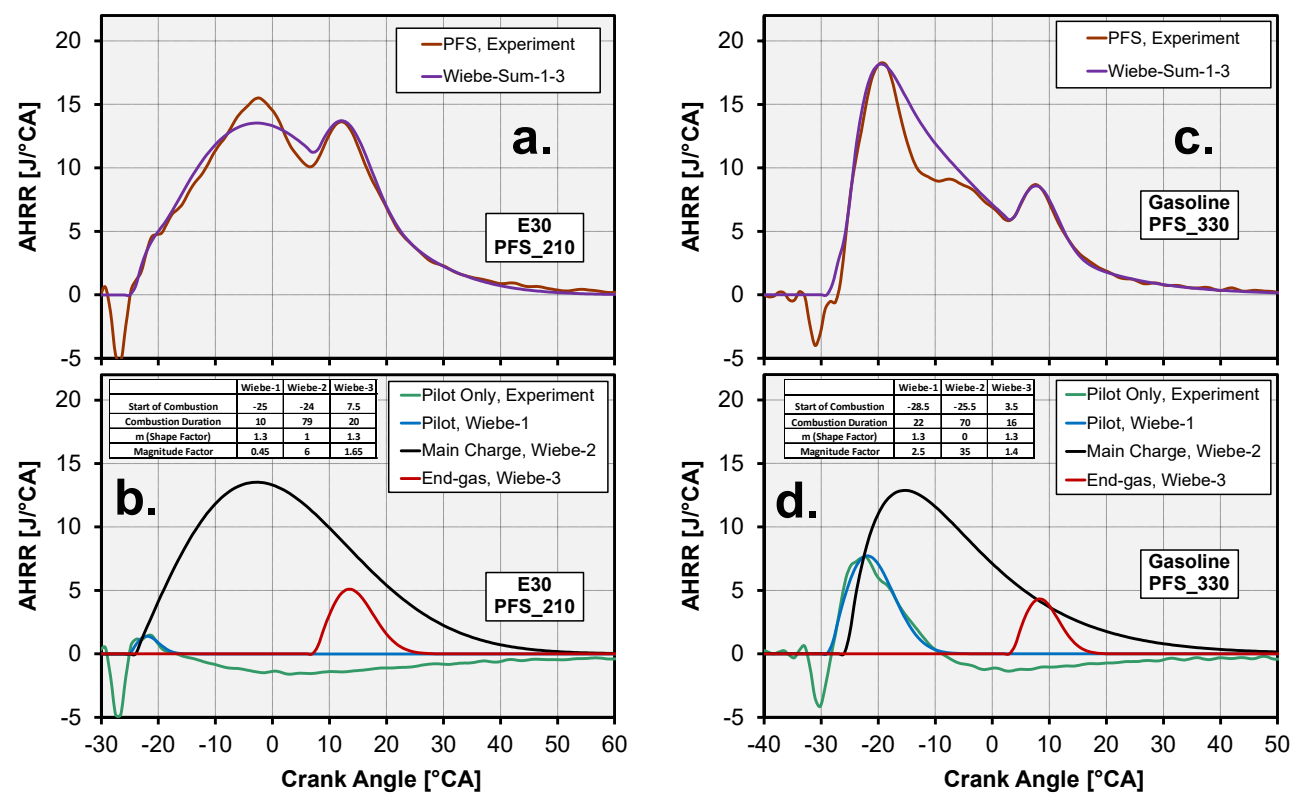

Figure A4. Reconstruction of the experimentally measured AHRR using a combination of three separate Wiebe functions for PFS_210 combustion case (a,b) and PFS_330 combustion case (c,d).

Figure A4b,d show the three Wiebe functions for each PFS case. These figures also show the experimentally derived AHRR for operation with pilot injection only (i.e., without early injections). These pilot-only AHRR traces are used to tune the shape and magnitude of the Wiebe-1 function for each case. Due to heat-transfer losses, the experimentally derived AHRR traces go negative after the main part of the pilot-only combustion event. These negative sections are ignored in the process of fitting the Wiebe- 1 functions. The experimentally based traces also show a negative dip at the time of pilot injection and spark timing. This is caused by a combination of vaporization cooling and noise from 
the spark discharge, both affecting the measured pressure traces and subsequent AHRR calculations. These negative dips are also ignored when fitting the Wiebe- 1 functions to the pilot-only AHRR traces. Subsequently, the shapes and magnitudes of the Wiebe- 2 and Wiebe- 3 functions are iteratively adjusted to create an approximate match between the experimental AHRR traces and the Wiebe-1-3 sums in Figure A4a,c. The inset tables in Figure A4 shows the final settings used for each Wiebe function.

The resulting decomposition of the experimental AHRR traces into three distinct phases can be used cautiously to aid the interpretation of the experiment. For example, Figure A4b shows that the pilot-enhanced combustion (Wiebe-1) is much weaker for the PFS_210 case with E30 compared to the PFS_330 case with gasoline. This is consistent with the much smaller amount of supplied chemical energy in the pilot injection for the PFS_210 case (31.8 J vs. $145 \mathrm{~J}$ ). With a much weaker enriched combustion, the total AHRR trace is dominated by deflagration in the lean main charge and this leads to a delay of the peak AHRR.

\section{References}

1. The 2019 EPA Automotive Trends Report (Greenhouse Gas Emissions, Fuel Economy, and Technology Since 1975), March 2020. Available online: https:/ / www.epa.gov/automotive-trends/download-automotive-trends-report (accessed on 28 November 2020).

2. Park, S.; Shin, J.Y.; Bae, C.; Jung, J.; Lee, J. Combustion Phenomena Affecting Particle Emission Under Boosting Conditions in A Turbocharged Gasoline Direct Injection Engine. Fuel 2021, 286 Pt 1, 119362. [CrossRef]

3. Kalwar, A.; Agarwal, A.K. Overview, Advancements and Challenges in Gasoline Direct Injection Engine Technology. In Advanced Combustion Techniques and Engine Technologies for the Automotive Sector; Singh, A., Sharma, N., Agarwal, R., Agarwal, A., Eds.; Springer: Singapore, 2020. [CrossRef]

4. Jung, D.; Sasaki, K.; Iida, N. Effects of Increased Spark Discharge Energy and Enhanced in-Cylinder Turbulence Level on Lean Limits and Cycle-to-Cycle Variations of Combustion for SI Engine Operation. Appl. Energy 2017, 205, 1467-1477. [CrossRef]

5. Sjöberg, M.; Zeng, W. Combined Effects of Fuel and Dilution Type on Efficiency Gains of Lean Well-Mixed DISI Engine Operation with Enhanced Ignition and Intake Heating for Enabling Mixed-Mode Combustion. SAE Tech. Pap. 2016. [CrossRef]

6. Schwarz, C.; Schünemann, E.; Durst, B.; Fischer, J. Potentials of the Spray-Guided BMW DI Combustion System. SAE Tech. Pap. 2006. [CrossRef]

7. Peterson, B.; Reuss, D.L.; Sick, V. On the Ignition and Flame Development in a Spray-Guided Direct-Injection Spark-Ignition engine. Combust. Flame 2014, 161, 240-255. [CrossRef]

8. Maurya, R.K. Premixed Charge Preparation Strategies. In Characteristics and Control of Low Temperature Combustion Engines. Mechanical Engineering Series; Springer: Cham, Switzerland, 2018. [CrossRef]

9. Sjöberg, M.; Dec, J. Smoothing HCCI Heat-Release Rates Using Partial Fuel Stratification with Two-Stage Ignition Fuels. SAE Tech. Pap. 2006. [CrossRef]

10. Hu, Z.; Zhang, J.; Sjöberg, M.; Zeng, W. The Use of Partial Fuel Stratification to Enable Stable Ultra-Lean DeflagrationBased Spark-Ignition Engine Operation with Controlled End-Gas Autoignition of Gasoline and E85. Int. J. Engine Res. 2020, 21, 1678-1695. [CrossRef]

11. Nakai, E.; Goto, T.; Ezumi, K.; Tsumura, Y.; Endou, K.; Kanda, Y.; Urushihara, T.; Sueoka, M.; Hitomi, M. MAZDA SKYACTIV-X 2.0L Gasoline Engine. In Proceedings of the 28th Aachen Colloquium Automobile and Engine Technology, Aachen, Germany, 25 October 2019.

12. Zeng, W.; Sjöberg, M.; Reuss, D.L.; Hu, Z. The Role of Spray-Enhanced Swirl Flow for Combustion Stabilization in a StratifiedCharge DISI Engine. Combust. Flame 2016, 168, 166-185. [CrossRef]

13. Sjöberg, M.; Dec, J.; Babajimopoulos, A.; Assanis, D. Comparing Enhanced Natural Thermal Stratification Against Retarded Combustion Phasing for Smoothing of HCCI Heat-Release Rates. SAE Tech. Pap. 2004. [CrossRef]

14. Grandin, B.; Ångström, H.; Stålhammar, P.; Olofsson, E. Knock Suppression in a Turbocharged SI Engine by Using Cooled EGR. SAE Tech. Pap. 1998. [CrossRef]

15. vafamehr, H.; Cairns, A.; Moslemin Koupaie, M. The Competing Chemical and Physical Effects of Transient Fuel Enrichment During Heavy Knock in an Optical SI Engine Using Ethanol Blends. SAE Tech. Pap. 2017. [CrossRef]

16. Yang, Q.; Liu, Z.; Hou, X.; He, X.; Sjöberg, M.; Vuilleumier, D.; Liu, C.; Liu, F. Measurements of Laminar Flame Speeds and Flame Instability Analysis of E30-Air Premixed Flames at Elevated Temperatures and Pressures. Fuel 2020, 259, 116-223. [CrossRef]

17. Braun, M.; Klaas, M.; Schröder, W. Analysis of Cyclic Variation Using Time-Resolved Tomographic Particle-Image Velocimetry. SAE Tech. Pap. 2020. [CrossRef]

18. Mehl, M.; (Lawrence-Livermore National Laboratory, Livermore, CA, USA). Personal communication, 2015.

19. Szybist, J.P.; Busch, S.; McCormick, R.L.; Pihl, J.A.; Splitter, D.A.; Ratcliff, M.A.; Kolodziej, C.P.; Storey, J.M.E.; Moses-DeBusk, M.; Vuilleumier, D.; et al. What Fuel Properties Enable Higher Thermal Efficiency in Spark-Ignited Engines? Prog. Energy Combust. Science 2021, 82, 100876. [CrossRef] 
20. Van Dam, N.; Zeng, W.; Sjöberg, M.; Som, S. Parallel Multi-Cycle LES of an Optical Pent-Roof DISI Engine Under Motored Operating Conditions. In Proceedings of the ASME 2017 Internal Combustion Engine Division Fall Technical Conference, Seattle, WA, USA, 15-18 October 2017. [CrossRef]

21. Mitroglou, N.; Nouri, J.M.; Gavaises, M.; Arcoumanis, C. Spray Characteristics of a Multi-Hole Injector for Direct-Injection Gasoline Engines. Int. J. Engine Res. 2006, 7, 255-270. [CrossRef]

22. Sjöberg, M.; Som, S.; Flowers, D. FT070, MM: Autoignition in MM/Advanced Compression Ignition (ACI) Combustion, Part 1. In Proceedings of the U.S. Department of Energy Vehicle Technologies Office 2019 Annual Merit Review and Peer Evaluation Meeting, Arlington, VA, USA, 10-13 June 2019.

23. Kim, N.; Vuilleumier, D.; Sjöberg, M. Effects of Injection Timing and Duration on Fuel-Spray Collapse and Wall-Wetting in a Stratified Charge SI Engine. SAE WCX Digit. Summits 2021. accepted.

24. Merola, S.S.; Irimescu, A.; Marchitto, L.; Tornatore, C.; Valentino, G. Effect of Injection Timing on Combustion and Soot Formation in a Direct Injection Spark Ignition Engine Fueled with Butanol. Int. J. Engine Res. 2017, 18, 490-504. [CrossRef]

25. Fansler, T.D.; Reuss, D.L.; Sick, V.; Dahms, R.N. Invited Review: Combustion Instability in Spray-Guided Stratified-Charge Engines: A Review. Int. J. Engine Res. 2015, 16, 260-305. [CrossRef]

26. Li, C.H.; Tam, P.K.S. An Iterative Algorithm for Minimum Cross Entropy Thresholding. Pattern Recognit. Lett. 1998, 18, 771-776. [CrossRef]

27. Glassman, I.; Yetter, R.A.; Glumac, N.G. Combustion, 5th ed.; Elsevier: Amsterdam, The Netherlands, 2014.

28. Johansen, L.C.R.; Hemdal, S. In cylinder visualization of stratified combustion of E85 and main sources of soot formation. Fuel 2015, 159, 392-411. [CrossRef]

29. Dieke, G.H.; Crosswhite, H.M. The Ultraviolet Bands of OH. J. Quant. Spectrosc. Radiat. Transf. 1961, 2, 97-199. [CrossRef]

30. Herzberg, G.; Johns, J.W.C. New Spectra of the CH Molecule. Astrophys. J. 1969, 158, 399-418. [CrossRef]

31. Pretty, W.E. The Swan Band Spectrum of Carbon. Proc. Phys. Soc. 1927, 40, 71-78. [CrossRef]

32. Gaydon, A.G.; Moore, N.P.W.; Simonson, J.R. Chemical and Spectroscopic Studies of Blue Flames in the Auto-Ignition of Methane. Proc. R. Soc. Lond. Math. Phys. Sci. 1955, 230, 1-19.

33. Tornatore, C.; Sementa, P.; Merola, S.S. Optical Investigations of the Early Combustion Phase in Spark Ignition Boosted Engines. Proc. Inst. Mech. Eng. D 2011, 225, 787-800. [CrossRef]

34. Ghojel, J.I. Review of the Development and Applications of the Wiebe Function: A Tribute to the Contribution of Ivan Wiebe to Engine Research. Int. J. Engine Res. 2010, 11, 297-312. [CrossRef] 